\title{
Investment Responses to Tax Policy Under Uncertainty
}

\section{WP 20/07 \\ July 2020}

\author{
Irem Guceri \\ University of Oxford \\ Maciej Albinowski \\ IBS
}

Working paper | 2019-2020

This working paper is authorised or co-authored by Saïd Business School faculty. The paper is circulated for discussion purposes only, contents should be considered preliminary and are not to be quoted or reproduced without the author's permission. 


\title{
InVESTMENT Responses to TAX Policy UNDER UNCERTAINTY*
}

\author{
Irem Guceri \\ University of Oxford
}

\author{
Maciej Albinowski \\ IBS
}

\begin{abstract}
How does economic uncertainty affect investment responses to tax policy? We exploit a natural experiment in which two very similar investment subsidies were implemented in the same country, two years apart: once during a period of economic stability, and once during a period of very high uncertainty. Exploiting sharp discontinuities in eligibility and using rich administrative data, we find that, under low uncertainty, tax incentives have strong positive effects on average investment. Under high uncertainty, however, the story is different: there is vast heterogeneity in investment responses, with the firms that are sheltered from elevated uncertainty still responding strongly to the policy, and the firms that are exposed to high uncertainty driving a drop in responses. This implies that periods of stability offer an important policy opportunity to encourage investment, and that the impact of stimulus in crises depends on the distribution of firms in their exposure to elevated uncertainty.
\end{abstract}

JEL CODES: H25, D25, C21

KEYWORDS: INVESTMENT, UNCERTAINTY, TAX POLICY

*Guceri: Corresponding author. Oxford University Centre for Business Taxation, Said Business School, Park End Street, OX1 1HP, Oxford, UK. irem.guceri@sbs.ox.ac.uk. Albinowski: Institute for Structural Research, Warsaw, Poland. We are extremely grateful for valuable comments by Michael Devereux, Peter Egger, Michael Kogler, Eric Ohrn, Dawid Pachucki, Juan Carlos Suarez Serrato, Simon Quinn and participants to the Oxford seminar, the CEPR Business Tax 2020 Workshop and the LMU seminar. We thank Emilia Skrok, reviewers from the World Bank and the World Bank seminar participants for comments on an earlier version. Irem Guceri thanks the British Academy for financial support under her Postdoctoral Fellowship. Any errors and omissions are the authors' own responsibility. This work contains statistical data from the Ministry of Finance of the Republic of Poland. The views expressed in the paper do not necessarily reflect those of the Ministry of Finance of Poland. 


\section{INTRODUCTION}

The effectiveness of any microeconomic policy is likely to depend upon the macroeconomic context. Both macro and micro uncertainty rise in recessions (Baker and Bloom, 2013; Bloom, 2014), and periods of high uncertainty, such as the global recession of 2008-09, or the Covid-19 crisis, call for a different optimal policy mix relative to normal times.

In this paper, we study the impact of a unique natural experiment in which two very similar investment tax incentives were implemented in the same country during periods of very different degrees of uncertainty. The first policy was implemented in a period of economic stability, and the second at a time of extremely high economic uncertainty. A sharp firm size cutoff determined eligibility to each scheme, generating natural treatment and control groups for each of the policies. We find that, under low uncertainty, tax incentives have strong positive effects on average investment. Under high uncertainty, however, the story is different: there is vast heterogeneity in investment responses, with the firms that are sheltered from elevated uncertainty still responding strongly to the policy, and the firms that are exposed to high uncertainty driving a drop in responses. Together, these results imply that: (i) periods of stability offer an important policy opportunity to encourage investment; and (ii) a larger share of firms "wait and see" during periods of high uncertainty relative to periods of low uncertainty, even in the presence of generous incentives. We rule out several alternative channels, including differential changes to financing constraints, companies suffering large losses in downturns, and the impact of fluctuations in terms of trade. To our knowledge, ours is the first paper to provide micro-level quasi-experimental evidence on the interaction between uncertainty and investment responses to stimulus policies.

To assess the influence of increased uncertainty as a possible channel, we construct a firm-level uncertainty exposure measure (a second-moment measure similar to those proposed by Bloom et al. (2018)) using administrative business population data from Poland. Our main identification strategy relies on the changes in the user cost of capital induced by two major reforms. Before the reforms, firms in Poland could depreciate the cost of machinery and equipment over 5-20 years using 'straight line' depreciation. First, in 2007, special depreciation provisions were introduced, which enabled companies with less than 800,000 Euros in turnover in the preceding year to benefit from 100 percent immediate deduction of the cost of machinery and equipment from taxable income. Second, in 2009, these benefits were extended to a group of medium-sized firms with turnover below 1.2 million Euros. As we discuss shortly, each of these reforms reduced the user cost of capital by about 8 percent: a reduction that should induce substantial investment 
impacts. We use rich administrative data on the population of corporate, personal and value added tax (VAT) returns of firms and a difference-in-differences methodology to estimate the investment responses of treated firms in each of the reform episodes. We control for (i) firm-specific time-invariant unobserved heterogeneity, (ii) importer- and exporter-specific time effects, (iii) the impact of annual changes in the macroeconomic environment that are unrelated to the reform of interest, (iv) sector-specific time effects and $(\mathrm{v})$ changes in firm size over time.

We find that, in the low volatility period, treated firms significantly increased investment spending by around 8 percent on average, in response to the reduced cost of capital. This finding translates to an estimated elasticity of investment to the user cost of capital of -5.2 in the period of low uncertainty. In the period of high uncertainty, the average elasticity estimate is smaller in magnitude with large standard errors. The imprecision in this latter estimate is driven by substantial heterogeneity across the firms that are more and less exposed to micro-level uncertainty. We estimate that the firms that are sheltered from elevated uncertainty continued responding to the policy, and increased their average investment by 12 percent (which is insignificantly different from the estimate from the low volatility period). Our estimates show that the response of the companies that are exposed to increased uncertainty was statistically indistinguishable from zero.

Empirical focus on the impact of second-moment shocks on real investment is relatively recent (Leahy and Whited, 1996; Bloom, 2009; Gulen and Ion, 2016). Heterogeneity in policy impact under varying degrees of uncertainty is implied in the more recent models such as the one by Bloom et al. (2018). Our approach is consistent with a real option model where delaying the acquisition of capital is analogous to a call option, and where uncertainty increases the value of a 'wait and see' strategy represented by this call option (e.g. Abel and Eberly (1996); Bloom, Bond and Van Reenen (2007)). When the wider economy goes through a downturn, firms face two separate shocks, which can be modelled by a negative first-moment shock and a positive second-moment shock to productivity. Thanks to the partial irreversibility of real investment projects, along with an imperfectly competitive product market, firms become cautious about investing when these uncertainty shocks hit. Firms disinvest if their productivity falls below a lower bound, invest if their productivity is above an upper bound, and take no action (or only undertake replacement investment) if they are in between these two thresholds. Under higher uncertainty, we empirically test that the 'exposed' firms fall in this kind of area of inaction. In this way, our paper speaks primarily to the issue of the short-run responses to changes in the tax price of investment. In the long run, to the extent that higher investment induced by the policy translates to higher output, our outcome variable may 
itself begin to influence assignment to treatment.

In recessions, companies are likely to simultaneously experience both an adverse firstmoment shock and a positive second-moment shock. Companies that incur losses may be less responsive to stimulus (Zwick and Mahon, 2017), not because of uncertainty, but because the value of a future tax benefit is lower than the value of an immediate benefit that is only available to profitable firms. We use the changes in companies' profitability and turnover to explore first-moment effects. We investigate whether our second-moment measure for uncertainty masks the first-moment measure of profitability. We find that taxable profit statuses of companies with varying degrees of exposure to elevated uncertainty move in parallel until the second reform episode. We measure micro-level exposure to uncertainty in the final pre-reform period of 2009, at which point the ratios of profitable to loss-making firms among both the more exposed and the less exposed groups are virtually the same. Among our main results, we also examine how the investment responses of companies change based on whether or not they are profitable, and whether profit- and loss-making sub-groups are exposed to uncertainty. We find that first-moment effects are important in determining investment responses to stimulus, and we also show that both profitable and loss-making firms are more likely to respond to stimulus if they are relatively sheltered from elevated uncertainty.

We explore several plausible alternative mechanisms. In addition to elevated uncertainty, we consider the role of differential changes in financing constraints and changes in terms of trade. There is a large empirical literature on financial frictions that highlights a negative relationship between firm size and the extent of financial frictions. ${ }^{1}$ To rule out differential changes in financing constraints during the crisis period, we first show evidence that credit supply during the crisis did not change differentially for different size groups in Poland. Second, we focus on mature firms for the whole estimation sample, as young firms are typically more financially constrained than established firms. We also use a narrow size range of companies, only including those firms just above and just below the size threshold for eligibility to more generous investment incentives. To explore the effect of the changes in terms of trade, we use the detailed import and export data and show that these do not drive the differential in results for the two reform

\footnotetext{
${ }^{1}$ Earlier descriptive works indicated differential investment impacts of access to external finance across different firm size groups (for example, Fazzari, Hubbard and Petersen (1988)), followed by more structural approaches and investigations into the mechanisms (for example, Whited (1992); Moyen (2004); Whited (2006); Hennessy and Whited (2007); Hoberg and Maksimovic (2015)). In addition to these studies, a number of papers explored other dimensions of the relationship between financing frictions and investment. For example, Farre-Mensa and Ljungqvist (2016) review and discuss the limitations of commonly-used measures of financing constraints, and Strebulaev and Whited (2012) review the literature on dynamic corporate finance models, including those that feature costly external financing.
} 
periods. We check robustness to isolating the investment responses of only domesticallytrading firms in the estimation sample. We conclude that uncertainty, rather than the other hypothesised channels, is key to explaining the differential effects of the two policy reforms.

We make three main contributions. First, we explore a novel aspect of firm responses to tax policy stimuli for investment: namely, the role of micro-level exposure to uncertainty. Ours is the first paper to explore this channel in a quasi-experimental setting with firm-level variation using administrative data. The literature on the impact of micro-level exposure to uncertainty on firms largely focuses on the heterogeneity in exposures of publicly traded stocks to uncertainty (see, for example, Bali, Brown and Tang (2017)). The issues surrounding listed companies' exposure to uncertainty differ from those surrounding unlisted companies, which are mostly small and medium sized enterprises (SMEs). The impact of uncertainty on investment responses may be driven by non-convex adjustment costs, or an initial fixed cost of investment (e.g. Cooper, Haltiwanger and Power (1999), Winberry (2018), Chen et al. (2019)).

Second, our findings offer new empirical support regarding the weaknesses of using permanent tax cuts for stimulus during downturns. This is particularly relevant given that tax cuts feature heavily in proposed stimulus packages during recessions. Many countries, such as the US and the UK, have been implementing policies that allow the deduction of the cost of capital in the year of their acquisition from taxable income (full expensing) rather than depreciating this cost over a number of years. ${ }^{2}$ From a theoretical perspective, Abel (1982), and later House and Shapiro (2008), argue that temporary tax incentives might induce stronger investment responses than do permanent measures. Comparable studies of temporary incentives find elasticities that are higher than 6 in absolute value (on US Bonus Depreciation, see Zwick and Mahon (2017) and on the UK First Year Allowance, see Maffini, Xing and Devereux (2019)). ${ }^{3}$

Third, we use a detailed linked dataset covering the population of VAT and corporate taxpayers, along with their import and export activity. The detailed data allows us to (i) test a number of different channels that may be contributing to the heterogeneity in responses in the second reform period, (ii) construct our uncertainty measure by exploiting the monthly frequency of our data, (iii) verify parallel pre-reform trends across treated and control groups for both experiments by using investment information at annual and

\footnotetext{
${ }^{2}$ The 2017 US tax reform and the UK's Annual Investment Allowance allow full expensing under certain conditions.

${ }^{3}$ Maffini, Xing and Devereux (2019) study a permanent incentive, and the authors point out that using realistic discount rates, they obtain estimates for elasticity of investment with respect to user cost around -4 .
} 
quarterly frequency, and (iv) control for a larger set of observable characteristics and trends than the existing literature.

The remainder of this paper is organized as follows. In Section 2, we summarise the institutional setup and explain our empirical strategy. In Section 5, we present our results and provide robustness checks. We then interpret our results in light of the existing literature and provide policy implications in Section 6. We conclude in Section 7.

\section{Institutional BACKGROUND AND EMPIRICAL STRATEGY}

\subsection{The Institutional CONTEXT}

Most corporate tax systems do not allow firms to deduct the full cost of capital goods from taxable income immediately. Instead, part of such costs can be deducted each year according to a depreciation schedule defined by the law. Until the introduction of the Lump Sum Depreciation scheme in Poland in 2007, the average time span over which the cost of machinery and equipment could be depreciated was around seven years. The scheme allowed eligible firms to deduct the full cost of qualifying capital goods, composed mostly of machinery and equipment, in the year in which the goods are purchased. From the outset, the policy was known to be permanent, and it is still in place. Both policies were announced shortly before their implementation, ruling out anticipation by potential beneficiaries. We present further detail on the institutional setup and announcement timelines in the Appendix.

Following the neoclassical optimal capital accumulation model (Hall and Jorgenson, 1967), we calculate the tax component of the cost of capital $u$ as: $\frac{1-\tau_{t} z_{i t}}{\left(1-\tau_{t}\right)}$, where $\tau_{t}$ is the statutory tax rate on corporate profits in year $t$ (this rate remained stable throughout our data period at 19 percent across all companies), and $z=\sum_{t=0}^{T-1}\left(\frac{1}{1+r}\right)^{t}(1 / T)$ per dollar of investment with total useful asset life (for tax purposes) captured by $T$, subject to straight line depreciation. ${ }^{4}$ There are two policies in place - and, ceteris paribus, each of the policies applied a similar reduction in the user cost of capital at different points in time on different groups of firms. Each of the reforms reduced the user cost of capital by around 8 percent on average.

As an example, a company that bought machinery at a cost of $€ 35,000$ before the

\footnotetext{
${ }^{4}$ For this simple calculation, we assume a total useful life of seven years for the capital good, and a fixed discount rate of $10 \%$.
} 
reform could only deduct $€ 5,000$ each year from its taxable income. At the stable 19 percent tax rate, the tax benefit from deducting $€ 5,000$ amounts to $€ 950$ per year, over an average of seven years. If we assume a discount rate of 10 percent, the present discounted value of all future tax deductions is $€ 5,087$. If the firm is allowed to deduct the full cost in the year of purchase, the tax gain is $€ 6,650$, yielding a net benefit of $€ 1,563$, or 4.5 percent of the purchase price of the asset. This might appear as a small cost reduction for capital goods with a short asset life (Desai and Goolsbee, 2004), but it is an important boost for the firms intending to acquire assets with longer useful lives. Even for assets with shorter useful lives, it may be sufficient to carry the marginal projects above the break-even point.

To benefit from the policy, a firm's total revenue in the preceding year must not exceed the threshold, which in 2007 was set at $€ 800,000 .^{5}$ In the middle of 2009 , the revenue cap for a small taxpayer rose to $€ 1.2$ million. We present the timeline of eligibility thresholds in Figure 1.

$$
<\text { Figure } 1>
$$

The annual limit for investment expenditures that could be deducted is set at $€ 50,000$, with the exception of 2009 and 2010, when it was increased to $€ 100,000$. This expansion renders the second reform more generous than the first one for our empirical analysis.

\subsection{EMPIRICAL STRATEGY}

We evaluate the performance of treated firms relative to control firms using difference-indifferences. We estimate the impact of the policy on the level of investment for treated firms, controlling for time-invariant firm-specific characteristics using a within-groups estimator. A firm is eligible for full expensing of the cost of its qualifying capital goods in year $t$ if its turnover in year $t-1$ was below the statutory size threshold.

Experiment 1 - the low volatility period: The first experiment is the introduction of the Lump Sum Depreciation scheme in 2007 for firms below the $€ 800,000$ turnover size threshold in 2006. We form the treatment group as the firms that fall below this size limit in 2006, which is the last pre-reform period. The control group consists of the firms that were above the threshold in the same year.

\footnotetext{
${ }^{5}$ Across the EU, thresholds for eligibility to such schemes have to be set in Euros for conformity with the EU State Aid requirements. To translate the threshold into Polish currency (PLN), the exchange rate from the first day of previous year's October is used. A newly established firm is also eligible to expense its capital spending, at least for the first year of its activity. We limit the sample of analysis to firms that were at least three years old at the start of our sample for a variety of reasons, including this concession for young firms regardless of size.
} 
Experiment 2 - the high volatility period: The second experiment is the expansion of the eligibility criterion to firms with turnover between $€ 800,000$ and $€ 1,200,000$ in mid-2009. We form the treatment group as the firms that had turnover below $€ 1,200,000$ in 2009, which is the last pre-reform period. The control group consists of the firms that were above the higher threshold of $€ 1.2$ million in the same year. Because 2009 is a partial treatment period, we remove this period from our analysis, but include it in the figures that demonstrate common trends. For the purpose of evaluating the investment response to the second reform, we exclude all the firms that were treated by the first reform in 2008, so the smallest firms do not enter the second experiment sample.

In Figure 2, we summarize the two possible treatment categorizations based on prereform size. For the first sub-sample, the control group is composed of both 'Control' and 'T-Mid', as labeled in the figure, as they are unaffected by the 2007 reform. When the second reform kicks in in the middle of 2009, medium sized firms in the 'T-Mid' group are also treated.

$<$ Figure $2>$

Because treatment status is a function of size, we consider the possibility that firms grow or shrink in systematic ways. We fix treatment status based on the final year pre-reform, for both experiment samples. We also exclude all firms that grew or shrunk by more than $40 \%$ between the final two years before the reforms took place. Akin to a matching procedure based on size, we retain the firms close to the size thresholds in the treated and control groups. ${ }^{6}$ Finally, we focus on the outcome observed in the first year after each reform year. These outcome years of interest are 2007 and 2010. We focus particularly on short-run outcomes, as treatment assignment in later years may be affected by feedback from policy-induced investment to firm size.

For every year $t$, eligibility for treatment is determined using firm size measured by turnover in year $t-1$. Turnover is a variable that fluctuates for each firm over time, generating the possibility of firms moving between treatment and control groups. A transition from treatment group under the first reform to control groups under the second reform would be potentially problematic in case adjustment to the initial treatment takes a few years. A transition from control status under the first reform to treatment status under the second reform should not reduce power for the second reform effects in the absence of cross-firm spillovers. We demonstrate movements between the groups across different reform periods in Table 1 . The rows of Table 1 capture the number of firms in treated and control groups respectively for the first reform period, and the values shown

\footnotetext{
${ }^{6}$ We drop the smallest half of treated firms and the largest half of control firms. The results are not sensitive to the choice of size cut-off points.
} 
are for the number of treated and control firms in the second reform period, as a share of the corresponding groups in the first reform period.

$<$ Table $1>$

The second reform was introduced three years after the introduction of the first policy. As an additional check for firm size changes in the run up to the second experiment, we construct an instrument that uses a simulated treatment assignment based on firm size in 2006 (final pre-first-reform period). The simulated treatment variable is a dummy that allocates treatment according to the policy thresholds for eligibility in the second reform period, applied to the firm size before the introduction of the first reform. We report the instrumental variables regression results along with our main results in Section 5.

We confirm that firms do not bunch below the size thresholds relevant for the two policies in Figure 3. This figure presents the post-reform distribution of firms relative to the turnover threshold in the preceding period; the density is clearly continuous across both policy cutoffs. ${ }^{7}$

$$
<\text { Figure } 3>
$$

Our main outcome of interest is the percentage increase in investment by the treated firms in the post-reform period, which we measure using the natural logarithm of investment. We also explore whether the reform increases the odds of investing for treated firms relative to control firms using a logit specification. Our baseline linear specification is the following:

$$
I_{i t}=\gamma D_{i} T_{t}+\mathrm{X}_{i t}^{\prime} \beta+\eta_{i}+\delta_{t}+\psi_{s t}+\varepsilon_{i t}
$$

For firm $i$ in year $t, I_{i t}$ is the outcome of interest (log of investment), $D_{i}$ is a timeinvariant dummy that takes the value unity for firms in the treated group, $T_{t}$ is a dummy that takes the value unity in the post-reform period. Therefore $D_{i} T_{t}$ represents 'Treatment $\times$ Post-reform' - a standard coefficient of interest in the typical diff-in-diff setup. $X_{i t}$ is a vector of time-varying characteristics such as turnover (in log), turnover quartiles (which non-parametically control for growth over time), the share of exports in turnover (pre-reform level) interacted with time, and share of imports in turnover (pre-reform level) interacted with time. The turnover threshold that determines assignment to $D_{i}$ is fixed in the last pre-reform period. Control variables included in $X_{i t}$ are lagged by

\footnotetext{
${ }^{7}$ The lack of bunching holds for all other analysis periods as well.
} 
one period. ${ }^{8}$ To prevent the effects of feedback from investment to turnover, we focus on short-run effects immediately after the reform. The other terms include time-invariant unobservable firm characteristics $(\eta)$, year dummies $(\delta)$, sector-year effects $\left(\psi_{s t}\right)$ and an error component $(\varepsilon)$. When the outcome variable is $\log$ (investment), the estimate $\hat{\gamma}$ can be interpreted as the change in investment for treated firms caused by the reform. In order to estimate the impact of the reform on the extensive margin, we use a similar set of explanatory variables as in Equation 1. ${ }^{9}$ We use a Poisson regression to estimate the total effect and conditional logit to estimate the effect of the policy on the (log) odds ratio of investing.

Our main approach relies on the distinction between firms that have access to the more generous policy and the firms that do not at all (as in Maffini, Xing and Devereux (2019) and Guceri and Liu (2019)). In addition to this exogenous policy-specific variation, the differences in weighted average asset life across narrowly defined sectors give a second source of exogenous variation (as in House and Shapiro (2008); Zwick and Mahon (2017) and Garrett, Ohrn and Suárez Serrato (2020)). For each firm, the longer the asset life of bulk of its capital stock, the larger is the impact of the policy on the firm's investment decisions. Our continuous treatment measure therefore replaces the interaction dummy variable $D_{i} T_{t}$ in Equation 1 with the time-varying user cost of capital for each firm-year observation to capture additional variation arising from differences in asset vintages across firms.

In order to assess the investment response under high uncertainty, we build on the baseline specification from Equation 1. We split the sample into two groups: belowand above-median exposure, based on the final pre-reform period exposure to firm-level uncertainty. In Equation 2, the coefficient on the triple interaction term $\gamma_{E}$ captures the differential impact on the 'more exposed' companies relative to the 'less exposed', while the coefficient $\gamma_{U}$ captures the effect on the companies that are less exposed. In regression results, we present the $p$-value for a test of the null hypothesis that the investment response by firms more exposed to elevated uncertainty, captured by the sum $\gamma_{U}+\gamma_{E}$, is equal to zero. $\gamma_{E}$ only takes the $i$ subscript as we fix the 'exposed' status for each subsample based on status at the final pre-reform period:

\footnotetext{
${ }^{8}$ For example, when the control variable is the share of exports in turnover interacted with time, the share of exports in turnover is taken as fixed at the last pre-reform period, and to capture any time effects, this lagged variable is interacted with year dummies.

${ }^{9}$ Convergence with a large number of control variables that have frequent zeros is computationally demanding in the conditional logit and Poisson specifications. We therefore control for the trade effects using the lagged share of exports and imports in turnover.
} 


$$
I_{i t}=\gamma_{U} D_{i} T_{t}+\gamma_{E} D_{i} T_{t} E_{i}+\theta_{T} T_{t} E_{i}+\mathrm{X}_{i t}^{\prime} \beta+\eta_{i}+\delta_{t}+\psi_{s t}+\varepsilon_{i t}
$$

In Section 4, we highlight the co-movements between first-moment and secondmoment factors during recessions that may be important in determining investment responses to stimulus policies. In order to distinguish between the two channels in affecting treatment effects, we estimate the following versions of our empirical specification:

1. Equation 1 with all controls, split by profit-or-loss status of companies in the treatment year. We run this analysis separately for both sample periods, Experiment 1 and Experiment 2.

2. Equation 1 with all controls in the preferred specification, adding a control for profit-or-loss status, separately for Experiment 1 and Experiment 2.

3. Equation 2 with all controls, split by profit-or-loss status of companies in the treatment year. We run this analysis for the high volatility period (Experiment 2).

4. Equation 2 with all controls in the preferred specification, adding a control for profit-or-loss status. We run this analysis for the high volatility period (Experiment $2)$.

\section{DATA}

\subsection{DATA SOURCES}

We use administrative data from the Ministry of Finance in Poland to assess the investment responses. The internal tax registry covers the period 2005-2016 and raw data is available on a monthly basis. We merge this information with the business register and micro-level trade data. We aggregate the monthly information to the annual level for the main analysis, and also examine common quarterly trends in investment across treated and control groups. Against the advantages of multiple sources of tax returns data that we highlight later, a drawback is the lack of information on the source of finance for investments. We also do not have data that provides information on asset types and other inputs.

VAT returns have been digitized since 2005 and this is the source of two key variables that we use in this paper: turnover and investment. ${ }^{10}$ In the VAT returns, firms are

\footnotetext{
${ }^{10}$ Turnover is composed of net values of all categories of sale (including those with the zero VAT rate) and the output VAT tax. Thus, the turnover is expressed in gross prices.
} 
obliged to declare the investment amount that is associated with any input VAT. VAT exemption thresholds are very low for the period of our study, and even for the smallest firms below the threshold, there is good reason to believe that those that carry out business-to-business transactions would have a strong incentive to register for VAT (Liu et al., 2018). We provide further details on the suitability of VAT data for our purposes in the Appendix.

We merge CIT data with VAT for further information on legal form, profit and loss positions. Almost all CIT taxpayers work with professional accountants to complete their tax return, which should increase the reliability of the data. We also expect the policy to be more salient for CIT taxpayers. Because of these advantages (and some others described in the Appendix), we focus predominantly on the population of CIT taxpayers.

Finally, we merge in the register of economic activity to obtain additional information at the firm-level, such as firm age, type and sector. We describe our data cleaning steps in the Appendix. In our final estimation sample, we focus on medium-sized firms by dropping the firms at both tails of the size distribution based on turnover in the last prereform period. We also remove young firms which have access to investment incentives regardless of size.

In the estimation sample, to ensure comparability of treated and control groups, we retain only the firms that are close to the eligibility cut-off. ${ }^{11}$ After all cleaning steps, we retain a comparable number of firms in treatment and control groups for the two samples. In our baseline regression samples, we retain 12,600 unique treated firms and 8,408 unique control firms for the low volatility period. For the high volatility period, we retain 3,209 unique treated firms and 7,546 unique control firms.

\subsection{SUMmary STATISTICS}

Table 2 reports the main characteristics of the two samples constructed to analyze each of the two reforms. The top panel of Table 2 presents the summary statistics for the low volatility period sample, and the bottom panel presents the summary statistics for the high volatility period. Firms in the second sample, which we use to evaluate the investment responses to the second reform, are on average a little larger than the firms

\footnotetext{
${ }^{11}$ We remove the largest half of the control group and the smallest half of the treated group. The reform set-up also means that the second reform places in the treated group a set of mid-sized firms in 2007 that became small in 2009, leaving a disproportionately large group of shrinking, failed firms in the treated group. To prevent such sample selection, we impose a restriction on turnover change. Firms are excluded from the second experiment if their turnover changed between 2007 and 2009 by more than $40 \%$. We use an analogous condition for the first experiment with regard to change in turnover between 2005 and 2006.
} 
that we use to analyze the outcomes in the first reform period. This is because we exclude all firms that were treated in 2008 based on their turnover in 2007 from the second experiment sample. $56 \%$ of the firms from the first sample and $72 \%$ of the firms from the second sample reported positive investment in the reference year. In both samples, manufacturing sector firms stand out as having the largest share of firms investing.

In the first pre-reform period, an average firm made an investment of 110,000 PLN, which translates to around $€ 27,000$. Average turnover of these firms was around 3.5 million PLN (around $€ 870,000$ ). There is also substantial international trading activity, which highlights the importance of controlling for changes in imports and exports due to changes in terms of trade in the analysis period.

$<$ Table $2>$

Plant-level investment is lumpy, and to the extent that there are many single-site firms in an economy, firm-level data should reflect the lumpiness. Earlier studies on the US and the UK note the rarity of zeros in firm-level investment data (Doms and Dunne, 1998; Caballero and Engel, 1999; Nilsen and Schiantarelli, 2003). The relatively larger share of non-investors in the absence of any special treatment for capital goods for Polish data helps in identifying extensive-margin effects when the reforms are implemented.

\section{QUANTIFYING FIRST-MOMENT AND SECOND-MOMENT SHOCKS}

Bloom et al. (2018) show that recessions typically feature simultaneous episodes of low output growth coupled with sharp increases in volatility. In such circumstances, the decline in output may be driven by demand-side or supply-side factors, or possibly both. In our context, the interplay between first-moment and second-moment shocks matter, as loss-making companies may be less likely to respond to tax incentives, even in the absence of second-moment effects.

In this section, we first explore the proxies available in the existing literature to quantify the effects of both first-moment and second-moment factors on investment (Section 4.1). Then, we explain how we measure both effects in monthly administrative tax returns data and provide some relevant descriptive statistics (Section 4.2). 


\subsection{Proxies IN THE EXISTING LiteRATURE}

In assessing investment responses to stimulus, tax returns data allows distinguishing across companies with different tax positions. While Edgerton (2010), using COMPUSTAT data, does not find a substantial dampening effect of tax loss status on investment responses to tax policy, Zwick and Mahon's 2017 analysis, using tax returns data, shows that profit-or-loss position matters for investment responses to an increase in the generosity of the tax treatment of investment: profitable firms are more responsive than loss-makers, in addition, responses diminish as the firms' accumulated loss carry-forwards increase.

With growing data availability, new and improved measures have emerged to capture different kinds of uncertainty (see, for example, Bloom, Baker and Davis (2016) for policy uncertainty, Jurado, Ludvigson and Ng (2015) and Beber, Brandt and Luisi (2015) for macroeconomic uncertainty, Jens (2017) for political uncertainty). In summarising the recent developments in the literature on quantifying second-moment shocks, we focus on measures of micro-level exposure to 'bad uncertainty', concentrating on increases in exposure to volatility that are coupled by adverse first-moment shocks (Bloom et al., 2018). ${ }^{12}$

Acknowledging the co-movement of business cycles and uncertainty, Bloom (2014) highlights the difficulty of separately identifying the individual effects of business cycle fluctuations and uncertainty on economic variables of interest. Leahy and Whited (1996) proxy for firm-level uncertainty using the variance of each firm's daily stock return within a year (scaled by each firm's debt-to-equity ratio, and the ex ante measure of uncertainty determined by a vector-autoregressive process). Bloom, Bond and Van Reenen (2007) and Bloom (2009) offer structural evidence on the dampening effect of uncertainty shocks on investment. In constructing their empirical proxies for elevated micro-level uncertainty, Bloom, Bond and Van Reenen (2007) closely follow Leahy and Whited (1996) and use the standard deviation of daily stock returns for each firm $i$ and year $t$ in their sample of 672 listed UK companies (thereby obtaining volatility measures for firm $i$ in year $t$, as we do in the present paper). Stock market-based measures need to account for bubbles or other sources of noise, and Bloom, Bond and Van Reenen (2007) normalize daily returns by the return on the FTSE All-Share Index to achieve this. Bloom (2009), Baker and Bloom (2013) and Alfaro, Bloom and Lin (2018) use similar stock

\footnotetext{
${ }^{12}$ There is a recent and growing line of research in volatility forecasting, for which the empirical applications rely on high-frequency data on listed companies. This line of literature merits a more in-depth discussion, which is beyond the scope of this paper. Segal, Shaliastovich and Yaron (2015) outline some of the important contributions in this area, and Bloom (2009) apply a jump test for stock market volatility as developed by Barndorff-Nielsen and Shephard (2005).
} 
market-based measures to Leahy and Whited (1996) and Bloom, Bond and Van Reenen (2007) to capture increases in firm-level uncertainty. Bloom (2009) also demonstrates the strong correlation between two cross-sectional micro-level volatility measures: (i) the stock market-based volatility measured by the standard deviation of monthly stock returns from CRSP data, and (ii) the standard deviation of profit growth (normalized by average sales in the current and the preceding quarter) in COMPUSTAT quarterly data. Finally, in addition to these second-moment measures, Guiso and Parigi (1999), Bachmann, Elstner and Sims (2013) and Gennaioli, Ma and Shleifer (2016) provide uncertainty measures that use micro-level business expectations survey data to explore the relationship between uncertainty and investment or output.

Bloom et al. (2018) examine the role of uncertainty over the business cycle. Their conceptual framework and the corresponding structural estimation procedures distinguish between aggregate and firm-specific sources of uncertainty, and they quantify these different sources of uncertainty using a variety of proxies. We outline here only two of their measures of micro-level volatility, as we believe these are the two measures that are the most closely-related to the one that we use in the present paper. Bloom et al. (2018) quantify micro volatility using: (i) the within-year standard deviation of quarterly sales growth at the firm-level obtained from COMPUSTAT, and (ii) a stock market-based measure similar to that of Leahy and Whited (1996) from CRSP, using monthly (and daily, as an alternative) returns over a year for every firm $i$ in year $t$.

\subsection{MEASURING UNCERTAINTY USING MONTHLY TAX RETURNS DATA}

Our administrative dataset has two advantages: first, it covers the entire population of firms, and second, it is available at monthly frequency for turnover and investment, and at annual frequency for company profits. We can therefore construct a plausible measure for firm-level exposure to volatility in line with the studies that we have discussed in Section 4.1, while controlling for some first-moment effects that are prevalent during recessions.

Our measure for micro-level exposure to uncertainty is the standard deviation of year-on-year growth rates in monthly turnover for each company $i$ in year $t$. We use yearon-year changes to rule out the effect of seasonality in driving the within-firm dispersion that we aim to quantify. ${ }^{13}$ The construction of this measure is in the spirit of the firmlevel studies that we cite in Section 4.1, but we use a sales growth-based measure rather

\footnotetext{
${ }^{13}$ To check robustness of using a particular uncertainty measure, we construct a second measure based on monthly changes in turnover for each company, then taking the relative standard deviation (coefficient of variation) of this measure for each firm-year. Results using this alternative measure lead to the same conclusions and are available upon request.
} 
than a measure based on stock returns, and information on much smaller firms than the US listed companies captured by the CRSP and COMPUSTAT datasets.

In Figure 4, we present the changes in firm-level exposure to volatility for the firms in our analysis sample. This graph demonstrates the increase in median firm-level exposure to uncertainty between the first reform period and the second reform period, pointing at around a 10 percent increase in firm-level volatility between the first and the second reform periods.

\section{$<$ Figure $4>$}

To analyse the differences between the companies that are exposed to uncertainty and the companies that are sheltered from uncertainty, we split our sample into two groups based on whether each company falls above or below the population median of the uncertainty measure in the final pre-reform period of 2009. We fix this classification in the final pre-reform period, and label each firm that faces above-median exposure to uncertainty as 'more exposed', and each firm that faces below-median exposure to uncertainty as 'less exposed'.

We begin by presenting descriptive statistics and trends on companies that are more exposed and less exposed to uncertainty within our high volatility period experiment sample. As we have discussed in Section 2.1, our sample includes mature firms, and therefore both the more exposed and the less exposed firms in the sample have an average age of around 9 years at the start of the sample. In Figure 5, we demonstrate the patterns in a series of variables that capture first-moment effects for each of the more exposed and the less exposed sub-groups. We depict average investment (in logs) in Panel (a), the share of profitable firms in Panel (b), average turnover in Panel (c) and the share of exporting and importing firms in Panel (d). These graphs demonstrate that there is a strong relationship between the trends in first-moment factors and firm-level exposure to uncertainty, verifying the findings of Bloom et al. (2018).

$$
<\text { Figure } 5>
$$

Finally, Figure 6 shows the representation of four broad sector categories within the more exposed and the less exposed groups. The share of manufacturing firms in each of the more exposed and the less exposed groups is roughly similar, with around a quarter of firms within each group belonging to the manufacturing sector. The largest difference in sector shares is observed in the construction and the trade and transport sectors. Construction sector firms constitute around 25 percent of all firms in the more exposed group, but they represent only 4 percent of all firms in the less exposed group. There are two likely reasons for the change in the share of construction sector firms across the two 
groups: first, the construction sector is typically harder-hit in recessions (Hoynes, Miller and Schaller, 2012), and second, the 2008-09 recession was particularly incident on the construction sector (housing, in particular). In our analysis, we control for sector-year trends to take into account the influence of sector-specific first-moment effects.

$<$ Figure $6>$

\section{Results}

\subsection{GraphicAl EVIDENCE}

We begin by graphing the pre-reform trends in average log investment for treated and control groups to examine the suitability of our quasi-experimental setup vis-à-vis the identifying parallel trends assumption. We check if the treated and control groups had similar changes in average investment before each reform in Figures 7 and 8, which show that the two series followed very similar pre-reform trends in both samples.

\section{$<$ Figure $7 \& 8>$}

We can do better than constraining ourselves to one year-on-year change prior to the first reform, thanks to the availability of higher-frequency data. In Figures 9 and 10, we use the quarter-on-quarter changes to inspect pre-reform trends for our comparison groups. The series follow overlapping trends in the pre-reform period, and Figure 9 shows that the treated group for the first experiment accelerated its average investment spending relative to the control group in the beginning of 2007 after the reform was introduced.

$<$ Figure $9 \& 10>$

We demonstrate the extent of time variation in macro uncertainty in Figure 11. The figure shows the changes in the Eurostat economic sentiment indicator, which is composed of indicators for confidence in several industries and a consumer confidence indicator. During the first reform year, this indicator peaks to its highest level within our data period, whereas the second reform period witnesses a dip followed by a relatively flat pattern that is much lower than the initial peak that we observe in the same graph. We present additional information on macroeconomic developments in Poland during our sample period in the Appendix.

$<$ Figure $11>$ 


\subsection{REGRESSION RESULTS}

Experiment 1 - the low volatility period: First, we test whether the introduction of the lump sum depreciation policy led to higher investment by the firms that are treated by the first reform in the low volatility period. We then gradually add various control variables to the specification in Equation 1. In Table 3, Column (1) includes firm and year fixed effects, and the coefficient on the variable labelled as 'Treated $\times$ Post-2006' captures the effect of the reform on the treated group relative to the counterfactual scenario. We find a positive and statistically significant effect of the reform on average investment (in log), corresponding to an impact of the policy on the intensive margin of around 8 percent.

Starting in Column (2), we include both the level of lagged turnover and control dummies for different quartiles in turnover to more flexibly control for changes in the firm size based on demand conditions. In Column (3), we add sector-year effects, whose inclusion does not have a substantial impact on the diff-in-diff coefficient estimate. In order to control for terms-of-trade effects induced by currency fluctuations, we introduce exporter- and importer-year effects in Column (4), which is our preferred specification.

$<$ Table $3>$

Experiment 2 - the high volatility period: In Table 4, Columns (1)-(4), we present the estimates from the same specifications as in Table 3, this time testing the impact of the second reform based on Experiment 2. The treated firms in the second reform are slightly larger than those treated in the first reform, and the maximum allowable expense for Lump Sum Depreciation is doubled, so ceteris paribus, we should see a larger increase in investment in response to the second reform. Conversely, we find reform effects that are smaller in magnitude relative to those based on Experiment 1, and estimated with wide confidence intervals. We present the $p$-value for the test of the coefficients on Treated $\times$ Post-reform at the bottom of Table 4 . The test shows that the reform effects in the two periods are not significantly different from each other. ${ }^{14}$

We then implement an instrumental variable (IV) strategy to account for any changes in firm size and the possibility of an interaction with the implementation of the first reform. To obtain the results in Column (5), we first assign simulated treatment using the thresholds for the second reform on firm size in the last period before the implementation of the first reform, in 2006. We use this simulated treatment variable as an instrument for treatment in the second reform period. The coefficient on Treated $\times$ Post 2009 using two-stage least squares is estimated to be 2 percent and statistically insignificant.

\footnotetext{
${ }^{14}$ We pool the two samples and test equal coefficients across the two reform periods.
} 
In Section 4.2, we have provided graphical evidence that the firms in our dataset experienced a sharp rise in uncertainty around 2009. In light of this observation, we now unpack our findings from the second reform period. The results in Columns (6) and (7) of Table 4 demonstrate that the firms which were sheltered from elevated uncertainty gave a strong average response to stimulus, whereas the firms that had high exposure to rising uncertainty did not respond to the policy at all. To arrive at this conclusion, we estimate the specification in Equation 2, which additionally interacts the diff-in-diff variable of interest ('Treated $\times$ Post-2009') with the dummy variable that captures the effect for firms that had a high exposure to uncertainty in the last pre-reform period. We also interact the 'High Exposure' dummy with the 'Post-2009' dummy to take into account the background change in the 'High Exposure' group between the pre-reform and the post-reform period that is unrelated to the reform. The coefficient on the uninteracted 'Treated $\times$ Post-2009' variable therefore can be interpreted as the effect of the reform for the firms that had low exposure to uncertainty. We do not reject the null hypothesis that the policy effect for the high exposure group was zero. Treated firms with a low exposure to increased uncertainty, on the other hand, responded strongly to the reform at similar magnitudes by two separate measures of uncertainty.

In Column (7), we confirm the lack of response by firms that had a high exposure to uncertainty through a Poisson regression, which takes the level of investment as explanatory variable and demonstrates the magnitude of the total of intensive and extensive margin responses. The coefficient on Treated $\times$ Post-2009 is positive and highly significant with a magnitude of 24.3 percent. High exposure firms, on the other hand, give a tight zero total response to policy, as captured by the coefficient on the triple-interaction term that almost exactly offsets the response by low-exposure firms. ${ }^{15}$ We conclude that the treated firms that had low uncertainty exposure increased their investment by around 12.2 percent in response to the introduction of the new policy.

First-moment effects: In Section 4, we have discussed that first-moment factors, as evidenced by Zwick and Mahon (2017), may be important in determining investment responses to tax policy stimuli. To test the impact of profit-or-loss status on investment responses to policy, we conduct a battery of tests in Table 5. In this table, Columns (1)-(6) all estimate the specification in Equation 1, but on different sub-samples. Specifically, in Column (1), we show the estimated investment response by profitable treated firms in the low volatility period. Profitable firms respond strongly in the low volatility

\footnotetext{
${ }^{15}$ Results using the alternative uncertainty measure and the full set of Poisson regression results which give similar estimates to the ones presented are available upon request.
} 
period: the point estimate for the coefficient on Treated $\times$ Post-reform is 8.4 percent and significant at the 95 percent level. In Column (2), we estimate the associated response by the companies that reported tax losses. The response by loss-makers is estimated much more imprecisely, but the estimated coefficient on Treated $\times$ Post-reform is still positive. The imprecision is likely driven by the heterogeneity across firms in their expected horizon for returning to profit and their stock of accumulated losses to be carried forward. Zwick and Mahon (2017) document such heterogeneity. ${ }^{16}$ In Column (3) of Table 5, we pool profitable and loss-making firms, but this time, we additionally control for profit status. This added control maintains the original difference-in-difference result that we have reported in Section 5.2.

\section{$<$ Table $5>$}

For the high volatility period, we report the analogous results in Column (4) for profitable companies, in Column (5) for loss-making companies and in Column (6) for the pooled sample with a control for profitability. Point estimates become smaller in magnitude and more imprecise relative to the low volatility period, for both profitable and loss-making companies. The diminished effect is more visible for the loss-making companies (Column (5)), which is in line with the argument that loss-makers are less likely to respond to fiscal stimulus. Importantly, during the high volatility period, even profitable companies have small and imprecise responses to the introduction of the new fiscal stimulus measure.

We then move on to show that our uncertainty indicator is not simply capturing the loss-makers' response to the lower cost of capital. To the contrary, both loss-making and profit-making firms give a stronger average response, if they are sheltered from elevated uncertainty. These results are visible in Columns (7), (8) and (9). In Column (9), controlling for profit or loss status, we find a statistically significant 12 percent differential impact of the policy on investment by firms that are sheltered from elevated uncertainty. The point estimates in the split samples (reported in Column (8) and Column (9)) are now more imprecise, but in all three columns, the signs and magnitudes of the coefficients of interest are remarkably aligned with our earlier conclusion that elevated uncertainty substantially reduces the effectiveness of fiscal stimulus for firms that are exposed to the elevated uncertainty.

The evidence that we have presented so far shows that the overall effect of an investment policy of this kind during a period of elevated uncertainty in an economy should depend on the distribution of firms in their exposures. Further evidence for this interpretation comes from exploring the investment responses of pass-through entities to the two

\footnotetext{
${ }^{16}$ Our dataset does not include information on the stock of losses to be carried forward.
} 
policy reforms. Pass-through entities are typically smaller, more likely to incur losses, have lower management quality and they operate predominantly in services and retail sectors. Examples are convenience stores, hairdressers, restaurants, plumbing or other household services, whose investment in fixed capital is usually lumpier and on average smaller in value relative to corporations. In Table 6 , we show that in the low volatility period, the reform induced a positive and significant increase in investment for treated pass-through firms, with a magnitude of around 13 percent (Column (1)). This effect goes all the way down to a tight zero for the high volatility period, which we demonstrate in Column (2). Because pass-through entities are more exposed to uncertainty as a whole, we do not observe a significantly positive effect of the reform even when we isolate the effect for the subset of treated pass-through entities that were subject to a relatively lower degree of uncertainty (Column (3)). It is impossible for us to distinguish first-moment effects in this case, as the data on profit is not available at the firm level. Finally, pass-through entities may learn about the policy more slowly, which would contribute to muted responses by this group of firms. ${ }^{17}$ However, if take-up was a primary driver of our results, then we should not have observed significant responses for the first reform either.

\section{$<$ Table $6>$}

Supplementary analyses: We now move to a supplementary analysis exploiting variation through a continuous treatment measure that has been explored in previous literature, following the theoretical predictions of the neoclassical optimal capital accumulation model (Hall and Jorgenson, 1967; Jorgenson, 1963). To align our specification with this model, we combine firm-level variation from our natural experiment with the variation that arises in treatment intensity at the sectoral level. Accelerated depreciation incentives induce an increase in aggregate investment by bringing the tax price of investment down. The impact is more pronounced for investment goods with long useful lives (Desai and Goolsbee, 2004; House and Shapiro, 2008; Maffini, Xing and Devereux, 2019; Zwick and Mahon, 2017). The reduction in the user cost of capital prompts an investment response by the beneficiaries. The investment responses are driven partly by the greater incentive to upgrade the capital stock thanks to the lower user cost of capital and partly, because tax incentives may relieve the cash flow constraint of firms with profitable investment opportunities but which previously could not invest due to the lack of sufficient funds.

\footnotetext{
${ }^{17}$ Evidence from the US suggests that pass-through entities have lower take-up rates than incorporated businesses for some special depreciation provisions (Kitchen and Knittel, 2016).
} 
Within our treatment group, this means that each firm is treated with different levels of intensity based on the share of long-lived assets within their capital acquisitions. We do not have information on the composition of assets at the firm level. We therefore use data on the shares of different asset types used by two-digit NACE sectors from the Central Statistical Office of Poland to estimate the elasticities of investment with respect to the user cost of capital. ${ }^{18}$ In Table 7 , Columns (1) and (3) cover the initial data period (2005-2007) and the remaining columns cover 2008-2010. In Column (1) and Column (2), we replace the diff-in-diff estimate with our continuous treatment variable to estimate the elasticity of investment with respect to user cost of capital, which we construct using a weighted average measure of the present discounted value of one Zloty of depreciation allowances. We estimate a log-log specification that yields direct estimates for the elasticity. Because we exploit both the introduction of the reform and the sectoral variation in treatment intensity, we assume that the non-tax components of the user cost term are absorbed by the quasi-experimental set up. We find that the user cost elasticity is between -3.7 and -5.2 , and statistically significant only in the low volatility period.

There are a number of reasons to expect measurement error in the empirical proxies for the user cost of capital (studied in Goolsbee (2000)). Measurement error in the user cost variable may lead to elasticity estimates that are biased toward zero. The tax rate that enters the user cost calculation is flat at 19\%, as there is no rate progressivity in Poland, and this rate has been stable throughout our sample period. Tax losses may also introduce some error in the calculation of the effective statutory tax rate, and therefore in Columns (3) and (4), we present the results from a regression with only the net present value of depreciation allowance $\left(z_{t}\right)$ replacing the user cost of capital as a proxy continuous treatment variable.

\section{$<$ Table $7>$}

Finally, we analyze the effects of the reforms on the log odds of investing for treated firms relative to control firms in the two reform periods using a conditional logit specification (Columns (5), (6) and (7)). In Column (5), which shows the reform effects in the low volatility period, we observe a strong and stable positive effect of the reform on the log odds of investing, but this effect becomes smaller in magnitude and more imprecise in the high volatility period (Column (6)). This is also consistent with Bloom, Bond and Van Reenen's 2007 finding that firms prefer to wait and evaluate future market conditions before taking investment decisions. These results are verified in Column (5), where the estimated coefficient on the triple interaction term 'Treated $\times$ Post-2009 $\times$

\footnotetext{
${ }^{18}$ Zwick and Mahon (2017) show, in their context, that using firm-level weights does not have a meaningful impact on their results.
} 
High Exposure' is negative and almost as large in magnitude as the effect on the firms with a low exposure to uncertainty.

\subsection{Robustness to Alternative Channels}

\subsubsection{Firm SIZE, GROWTH AND INVESTMENT OVER THE SAMPLE PERIOD}

As an initial robustness check, we conduct placebo tests in which we remove all treated firms and assign a placebo size threshold in the middle of the pre-reform size distribution of the control group. If we find that smaller firms within the control group increase investment spending after the reform, then this may signal a violation of our size-based treatment assignment. This initial placebo analysis tests for any mechanism that may relate to firm size, such as financing constraints or issues related to scale of investment. In Section 5.3.2, we explicitly analyze financing constraints as a possible alternative channel to explain our findings.

Table 8 presents the results from specifications that interact the time-invariant 'placebo treatment group' with the post-reform period dummy. We construct the samples for this analysis using only the control group firms for Experiment 1 and Experiment 2. The results in this table confirm a tight zero effect of the placebo reform on control firms split by size for both experiments. In addition, both the intensive margin placebo effect (Columns (1) and (2)) and the total placebo effect captured by the Poisson specification in Columns (3) and (4) are zero, regardless of the level of volatility (high or low).

$<$ Table $8>$

In order to address any concerns about differential growth rates by different size groups, we again drop all firms that were treated in the 2008-2010 period and focus only on the control group. Within this group, we slice the data up into different size categories based on their pre-reform size. We run the following regression:

$$
y_{i t}=\phi_{0}+\phi_{1} G_{1}+\phi_{2} G_{2}+\phi_{3} G_{3}+\eta_{i}+\delta_{t}+\psi_{s t}+\varepsilon_{i t}
$$

In Equation 3, $y_{i t}$ is the change in log turnover. We follow a similar specification to that in Equation 1 in terms of control variables, and we include size group dummies $G_{1}, G_{2}$ and $G_{3}$. The coefficients $\phi_{1}, \phi_{2}$ and $\phi_{3}$ capture the deviations from growth in the largest quartile within the control group. We then test whether each of the group coefficients is significantly different from zero, and also whether the coefficients are equal to each other. The coefficient estimates for each group is very small, and the $p$-value 
of the joint test of equal coefficients on different size bands is 0.971. This provides reassurance that we do not observe significantly different growth trends during the crisis by different adjacent size groups in our dataset. Figure 12 shows the point estimates and the 95 percent confidence intervals around the estimates for the $\phi$ coefficients.

$$
<\text { Figure } 12>
$$

\subsubsection{Financing CONSTRAints: Did The Global LiQUidity CRISIS HaVE A DIFFERENTIAL IMPACT ON TREATED AND CONTROL FIRMS?}

In our context, a natural question is whether different size categories of firms were affected differently by the adverse economic conditions in the second treatment period. Among others, Hennessy and Whited (2007) suggested that financing constraints may differ across firm size categories. If financing constraints are more severe for mediumsized companies relative to larger companies, then we may expect the liquidity crisis to hit the treated group differentially more, leading to a reduced investment response.

When we examine the changes in financing structures of different firm size categories using data from Statistics Poland on balance sheets of small, medium and large companies separately, we observe that there is no significant change in the debt ratios of different size groups of firms (Figure 13). If anything, debt-to-tangible net worth of larger companies has slightly declined between pre- and post-crisis periods. If there were any impact of the credit channel on policy responses, it would have been towards finding an investment response by medium sized firms relative to larger firms. We observe no such effect.

\section{$<$ Figure $13>$}

In our regressions, we safeguard against the differential crisis impacts on treated and control in several ways. First of all, our main estimation sample does not include very small, very large or newly-established firms. This is important given the positive relationship between firm size and investment frequency (Nilsen and Schiantarelli, 2003). We narrow down the size bracket for analysis by dropping the smallest $50 \%$ of the firms in the treatment group and the largest $50 \%$ of the firms in the control group, with both filters applied based on turnover in the last pre-reform period. Second, we only focus on mature firms at least 5 years after establishment. ${ }^{19}$ Given that financing constraints are more prominent amongst younger firms, the mature-firm focus provides a safeguard against adverse changes in financing options for different age categories. Third, the

\footnotetext{
${ }^{19}$ This was required independently of a financing constraint concern. The institutional set-up allows some benefits to younger firms, and we filter out the firms that may be eligible for such benefits.
} 
placebo tests that we have described in Section 5.3.1 provide an additional check to rule out differential changes to financing constraints by firm size groups.

\subsubsection{TERMS OF TRADE}

For firms that internationally trade in goods, the 2008-2009 period saw large changes in relative prices. Ceteris paribus, Polish exporters benefited from the depreciation of the Polish Zloty relative to the Euro and other major currencies. Conversely, importers saw their import prices rise during the same period. We may therefore expect companies engaged in international trade to be differentially affected by the changes in terms of trade.

To address any confounding impact on firms engaged in international trade, in Table 9, we present three versions of our results that relate to the impact of uncertainty on investment responses. Column (1) restates our baseline result on firms that have a high exposure to uncertainty, relative to those firms that are sheltered from uncertainty. In Column (2), we remove the importer- and exporter-year effects which we include as a standard control in our preferred specifications. Finally, in Column (3), we show the results on companies that did not have a substantial trading activity in the pre-reform period. We find that, when both the control and the treated samples are restricted to non-trading companies, the gap between the investment responses of companies that are exposed to and sheltered from elevated uncertainty widens even further. Companies that are exposed to uncertainty do not give a statistically significant response to the reduced cost of capital, as demonstrated by the $p$-value of the test on the sum of the two relevant coefficients being equal to zero. Non-trading companies that have a low exposure to elevated uncertainty increase their investment by 18.3 percent in response to the exogenous reduction in the user cost of capital.

$<$ Table $9>$

\section{Discussion}

\subsection{ThEORETICAL FOUNDATIONS FOR OUR RESUltS}

Three characteristics of investment are important for our empirical results. First of all, in practice, investment is at least partially irreversible (as modelled and documented in, for example, Arrow (1968), Bertola and Caballero (1994), Abel and Eberly (1996), Eberly and Van Mieghem (1997), Cooper and Haltiwanger (2006), Chetty (2007), Bloom, Bond and Van Reenen (2007), Bond, Söderbom and Wu (2011), Gulen and Ion (2016)). 
Second, the future payoff from an investment project is uncertain (Zeira, 1987; Caballero, 1991; Guiso and Parigi, 1999; Chetty, 2007). And third, firms can decide on whether or not to invest - and, if investing, when to make the investment (Abel et al., 1996).

A model that reflects all these characteristics of investment is laid out by Bloom et al. (2018), where each firm invests in capital goods and incurs adjustment costs that depend on a fixed component and a resale loss that reflects partial irreversibility. Under higher uncertainty, we expect 'exposed' firms to slow down investment activity. For the case of investment in physical capital, this may also mean that firms maintain a certain level of replacement investment, but do not take on new projects until the period of high uncertainty subsides. Empirically, this would be reflected in the continuation of similar levels of intensive margin investment by firms that are already investing, but that show no reaction to additional incentives, which government policies may aim to stimulate precisely during a downturn. Bloom et al. (2018) simulate policy impacts both in the presence and in the absence of uncertainty. With the rise of uncertainty, we may expect that the overall response to a stimulus policy may be muted relative to the response in a normal period.

The distinction between 'good' and 'bad' uncertainty is important for our results. Bloom et al. (2018) emphasize the need to consider the negative first-moment shock together with the positive second-moment shock to productivity in modeling recessions. Segal, Shaliastovich and Yaron (2015) show that high uncertainty is expected to worsen economic outcomes only when it is associated with negative innovations to growth. Empirically, we find the adverse impact of micro-level exposure to uncertainty on investment responses during the global recession, but not in the high-growth, low uncertainty period of 2007 when the first reform took place. ${ }^{20}$

\subsection{INVESTMENT RESPONSES RELATIVE TO COMPARABLE ESTIMATES IN THE LITERATURE}

We have begun our analysis by confirming some established findings of the existing literature, mostly referring to quasi-experimental estimates since Cummins, Hassett and Hubbard (1994). Recent availability of administrative data has greatly broadened our understanding of the effectiveness of tax incentive policies (House and Shapiro, 2008; Maffini, Xing and Devereux, 2019; Ohrn, 2018), including our understanding of heterogeneities in policy effects across such dimensions as size, age or profitability (Zwick and Mahon, 2017; Guceri and Liu, 2019; Agrawal, Rosell and Simcoe, 2019; Dechezlepretre

\footnotetext{
${ }^{20}$ These results are available upon request.
} 
et al., 2016). Firms are also heterogeneous in their exposure to uncertainty (Bloom, 2014; Awano et al., 2018). We have analysed the responses, first in a low-volatility environment, and later in a high-volatility environment and have found that macroeconomic conditions matter for micro-level heterogeneity in responses to policy.

The regression results provide a robust finding that average investment increases in response to a permanent tax incentive for the average firm during periods of stability. The effect during periods characterized by a negative first-moment shock and a positive second-moment shock, however, depends on the background economic conditions and the degree of firms' exposure to uncertainty. The distribution of firms in the economy therefore is an important consideration for governments to assess the suitability of a tax allowance measure to stimulate investment in downturns.

We have verified our results using the cross-industry variation in the composition of capital goods as in Zwick and Mahon (2017) and Garrett, Ohrn and Suárez Serrato (2020). This latter method has also allowed us to exploit treatment intensity at the sectoral level. According to these direct estimates of the elasticity of investment with respect to user cost exploiting both the quasi-experimental variation arising from the reforms in 2007 and 2009 and the continuous treatment variation across sectoral asset use, we find that the elasticity of investment with respect to user cost is between 3.7 and -5.2 , which is close to (though slightly lower than) the estimates of Zwick and Mahon (2017), Ohrn (2018) and Maffini, Xing and Devereux (2019). This range of estimates is higher than the ranges reported in some earlier studies, referenced in the review by Hassett and Hubbard (2002), who report estimates up to around -1 . The studies referenced in Hassett and Hubbard (2002) use data on listed companies, which are typically much larger than the small and medium-sized companies that we study. Our estimates pin down the impact mostly for SMEs, which may give different responses to incentives than the largest companies. We expect homogeneous adjustment to the new equilibrium investment levels. If smaller companies are slower in learning about the policy, we may expect a downward bias in our short-run estimates, but this should be more pronounced for the case of the first reform, given that the first reform applies to smaller companies than the second reform. This would favour a relative downward bias in the results from the first experiment, which does not appear to be the case. We are cautious to extend the analysis beyond the short-run results, since turnover in subsequent years might be affected by the investment levels induced by the policy itself. If the policy induces higher investment, which then induces higher productivity and turnover, then an analysis on later years' investment outcomes would no longer be immune to endogeneity arising from this feedback from our outcome variable of interest to treatment assignment based on $t-1$ turnover. 


\subsection{Policy costing, efFiciency and macroeconomic IMPLICATIONS}

Cost-effectiveness for the government varies according to when the reforms are implemented, and for the second reform, it also depends on the distribution of the firms in their exposure to the elevated uncertainty. We assume that the government borrows to make up for the cost of foregone revenue in the first period when a firm expenses the full cost of the asset purchased. On one hand, the government foregoes some revenue in the expensing year; on the other hand, the firm no longer has any depreciation expense for tax purposes starting with the second year of the asset's useful life. The government makes up for the nominal value of the foregone tax revenue in the subsequent periods and therefore needs to borrow less in these years relative to the absence of the policy. In this setting, the cost to the government of an accelerated depreciation policy has two components: (1) the cost of borrowing, (2) the cost arising from the time value of money due to discounting of future gains. We take both these costs into account to derive the return (in dollars of investment terms) from a dollar cost to the government.

The results based on the impact of the reform in the low volatility period show that the government has stimulated around 5.9 dollars of investment in machinery and equipment for every dollar of cost that it incurred. We calculate the total additional investment by corporations solely attributable to treatment, assuming that all treated firms respond in the same way as the average firm. The policy applies to all investing companies in the treatment group, and therefore the cost arises from all treated firms that would have still invested even in the absence of the policy. We calculate that the treated firms in our sample increased aggregate investment by 39.7 million Zlotys (little more than 10 million USD) thanks to the policy. In the absence of the policy, the government collects the same amount over 7 years, which is the average depreciation period for machinery and equipment. We calculate that the related borrowing need of the government is 41.2 million Zlotys in 2007, and the overall discounted cost of servicing debt amounts to 6.8 million Zlotys. Therefore, 1 dollar spent by the government translates to around 5.9 dollars of additional investment made by firms. For the purpose of this exercise, we fix the interest rate at the period average when calculating the government's borrowing costs. In sum, periods of stability offer an important policy opportunity to encourage investment.

During the period of high uncertainty, the policy on average did not induce statistically significant investment that would have otherwise not taken place. Our results indicate that the firms less exposed to uncertainty increased their investment by $12.2 \%$. Given our distribution of firms, with $53 \%$ of pre-reform investment being made by less 
exposed firms, we estimate that one dollar cost to the government yielded 5.2 dollars of additional investment. The cost-effectiveness of the reform would worsen if there were fewer firms sheltered from elevated uncertainty. For example, if only $25 \%$ of firms had responded to the policy, the government would have stimulated around 2.5 dollars of

additional investment for every dollar of related cost. We should expect uncertainty to further increase the cost of the policy if the government has limited knowledge about the distribution of companies' exposure to uncertainty.

The macroeconomic policy implications of our quasi-experimental results are tied to the question about which fiscal policies result in higher growth during recessions. Ramey (2019) gathers evidence from stimulus packages adopted following the 2008-09 crisis to compare the size of fiscal multipliers. Regarding tax policy instruments, evidence points toward large multipliers during expansions, but the magnitudes of estimated multipliers are smaller than or equal to unity during recessions. Our findings show that elevated uncertainty may be contributing to the lower multipliers for tax policy during recessions, limiting the impact of supply-side stimulus measures such as investment tax incentives during downturns. In such periods, demand-side instruments such as direct government spending may be more effective in generating output, at least in the short run (Auerbach and Gorodnichenko, 2012, 2013). The effectiveness of such demand-side instruments in turn depends on a multitude of factors such as the level of a country's development, openness of the economy and the size of public debt (Ilzetzki, Mendoza and Vegh, 2013; Mineshima, Poplawski-Ribeiro and Weber, 2014).

\section{Conclusion}

This paper uses two separate quasi-experiments to demonstrate that investment responses to permanent tax policy stimuli depend on micro-level exposure of firms to economic uncertainty. Specifically, we find evidence that elevated uncertainty may cause a dampening of investment responses to tax policy, consistent with the increased real option value of postponing investment under uncertainty. The gradual introduction of the same policy to different groups of firms in two separate points in time enables us to observe the effects first in a low volatility period and then in a high volatility period. We exploit two major reforms that took place in 2007 and 2009 with simple firm size cut-offs dictated by the policy for identification. We verify our results using a continuous treatment variable based on sectoral variation in treatment intensity. We use population data on VAT, CIT and international trade to apply our difference-in-difference estimator. We rule out other possible channels such as persistent company losses, heterogeneities in financing constraints during the financial crisis or the effect of changes in terms of trade 
on investment.

We first verify a key existing finding in the literature: that companies do respond to tax incentives for investment. A permanent reduction in the user cost of capital induced by a policy allowing for 100 percent expensing of the cost of capital goods leads to both an increase in average investment for firms that are already investing, and to an increase in the odds of investing for eligible firms that did not invest before the reform. We then explore responses to policy under different market conditions, thanks to the availability of the second reform in 2009. In this alternative setting, firms' responses to investment incentives depend on demand conditions. Companies that are exposed to a high degree of uncertainty do not respond to the policy at all. In contrast, the impact of stimulus is maintained for firms that are not highly exposed to uncertainty in high volatility periods.

The decline in the response under uncertainty is consistent with Bloom, Bond and Van Reenen's 2007 finding that firms prefer to wait and evaluate future market conditions before taking investment decisions. Our novelty is the empirical support for varying degrees of investment response to tax policy stimulus; studies to-date have mostly focused on either a single low volatility-period reform (such as Maffini, Xing and Devereux (2019)) or periods of high economic volatility (such as Zwick and Mahon (2017), who explore the impact of temporary incentives).

In this paper, we extend recent empirical findings about heterogeneities in firmlevel responses to tax policy to consider firms that face varying degrees of underlying uncertainty. Our results have important policy implications. While periods of stability offer an important opportunity to encourage private sector's investment in machinery and equipment, tax policy stimuli adopted in downturns may not be as effective. Aggregate investment movement in response to stimulus is likely to depend on the distribution of firms in their exposure to elevated uncertainty. 


\section{REFERENCES}

Abel, Andrew, and Janice Eberly. 1996. "Optimal Investment with Costly Reversibility." Review of Economic Studies, 63(4): 581-593.

Abel, Andrew B. 1982. "Dynamic effects of permanent and temporary tax policies in a q model of investment." Journal of Monetary Economics, 9(3): 353 - 373.

Abel, Andrew B., Janice C. Eberly, Avinash K. Dixit, and Robert S. Pindyck. 1996. "Options, the Value of Capital, and Investment*." The Quarterly Journal of Economics, 111(3): 753-777.

Agrawal, Ajay, Carlos Rosell, and Timothy S. Simcoe. 2019. "Tax Credits and Small Firm R\&D Spending." American Economic Journal: Economic Policy.

Alfaro, Iván, Nicholas Bloom, and Xiaoji Lin. 2018. "The Finance Uncertainty Multiplier." National Bureau of Economic Research Working Paper 24571.

Arrow, K.J. 1968. "Optimal Capital Policy with Irreversible Investment, Value, Capital and Growth, Papers in Honour of Sir John Hicks." , ed. J.N. Wolfe, 1-19. Edinburgh: Edinburgh University Press.

Auerbach, Alan J., and Yuriy Gorodnichenko. 2012. "Measuring the Output Responses to Fiscal Policy." American Economic Journal: Economic Policy, 4(2): 1-27.

Auerbach, Alan J., and Yuriy Gorodnichenko. 2013. "Output Spillovers from Fiscal Policy." American Economic Review, 103(3): 141-46.

Awano, Gaganan, Nicholas Bloom, Ted Dolby, Paul Mizen, Rebecca Riley, Tatsuro Senga, John Van Reenen, Jenny Vyas, and Philip Wales. 2018. "A Firm-level Perspective on Micro- and Macro-level Uncertainty." ESCoE.

Bachmann, Rudiger, Steffen Elstner, and Eric R. Sims. 2013. "Uncertainty and Economic Activity: Evidence from Business Survey Data." American Economic Journal: Macroeconomics, 5(2): 217-49.

Baker, Scott R, and Nicholas Bloom. 2013. "Does Uncertainty Reduce Growth? Using Disasters as Natural Experiments." National Bureau of Economic Research Working Paper 19475.

Bali, Turan G., Stephen J. Brown, and Yi Tang. 2017. "Is economic uncertainty priced in the cross-section of stock returns?" Journal of Financial Economics, 126(3): 471-489. 
Barndorff-Nielsen, Ole E., and Neil Shephard. 2005. "Econometrics of Testing for Jumps in Financial Economics Using Bipower Variation." Journal of Financial Econometrics, 4(1): 1-30.

Beber, Alessandro, Michael W. Brandt, and Maurizio Luisi. 2015. "Distilling the macroeconomic news flow." Journal of Financial Economics, 117(3): 489 - 507.

Bertola, Guiseppe, and Ricardo Caballero. 1994. "Irreversibility and Aggregate Investment." Review of Economic Studies, 61(2): 223-246.

Bloom, Nicholas. 2009. "The Impact of Uncertainty Shocks." Econometrica, $77(3): 623-685$.

Bloom, Nicholas. 2014. "Fluctuations in Uncertainty." Journal of Economic Perspectives, 28(2): 153-76.

Bloom, Nicholas, Max Floetotto, Nir Jaimovich, Itay Saporta-Eksten, and Stephen J. Terry. 2018. "Really Uncertain Business Cycles." Econometrica, 86(3): 1031-1065.

Bloom, Nicholas, Scott R. Baker, and Steven J. Davis. 2016. "Measuring Economic Policy Uncertainty." The Quarterly Journal of Economics, 131(4): 1593-1636.

Bloom, Nick, Stephen Bond, and John Van Reenen. 2007. "Uncertainty and Investment Dynamics." The Review of Economic Studies, 74(2): 391-415.

Bond, Stephen R., Måns Söderbom, and Guiying Wu. 2011. "Pursuing the wrong options? Adjustment costs and the relationship between uncertainty and capital accumulation." Economics Letters, 111(3): 249 - 251.

Caballero, Ricardo. 1991. "On the Sign of the Investment-Uncertainty Relationship." American Economic Review, 81(1): 279-288.

Caballero, Ricardo J., and Eduardo M. R. A. Engel. 1999. "Explaining Investment Dynamics in U.S. Manufacturing: A Generalized (S,s) Approach." Econometrica, 67(4): 783-826.

Chen, Zhao, Xian Jiang, Zhikuo Liu, Juan Carlos Suárez Serrato, and Daniel Xu. 2019. "Tax Policy and Lumpy Investment Behavior: Evidence from China's VAT Reform." National Bureau of Economic Research Working Paper 26336.

Chetty, Raj. 2007. "Interest Rates, Irreversibility, and Backward-Bending Investment." Review of Economic Studies, 74(1): 67-91. 
Cooper, Russell, John Haltiwanger, and Laura Power. 1999. "Machine Replacement and the Business Cycle: Lumps and Bumps." American Economic Review, 89(4): 921-946.

Cooper, Russell W., and John C. Haltiwanger. 2006. "On the Nature of Capital Adjustment Costs." The Review of Economic Studies, 73(3): 611-633.

Cummins, Jason G., Kevin A. Hassett, and R. Glenn Hubbard. 1994. "A Reconsideration of Investment Behavior Using Tax Reforms as Natural Experiments." Brookings Papers on Economic Activity, 25(2): 1-74.

Dechezlepretre, Antoine, Elias Einio, Ralf Martin, Kieu-Trang Nguyen, and John van Reenen. 2016. "Do Tax Incentives for Research Increase Firm Innovation? An R\&D Design for R\&D." Centre for Economic Performance CEP Discussion Paper 1413.

Desai, Mihir, and Austan Goolsbee. 2004. "Investment, Overhang and Tax Policy." Brookings Papers on Economic Activity, 2: 285-355.

Doms, Mark, and Timothy Dunne. 1998. "Capital Adjustment Patterns in Manufacturing Plants." Review of Economic Dynamics, 1(2): 409-429.

Drozdowicz-Biec, Maria. 2011. "Reasons Why Poland Avoided the 2007-2009 Recession." Research Institute for Economic Development, Warsaw School of Economics.

Eberly, Janice, and Jan Van Mieghem. 1997. "Multi-factor Dynamic Investment under Uncertainty." Journal of Economic Theory, 75(2): 345-387.

Edgerton, Jesse. 2010. "Investment Incentives and Corporate Tax Asymmetries." Journal of Public Economics, 94(11): 936 - 952.

Farre-Mensa, Joan, and Alexander Ljungqvist. 2016. "Do Measures of Financial Constraints Measure Financial Constraints?" The Review of Financial Studies, 29(2): 271 .

Fazzari, Steven, R. Glenn Hubbard, and Bruce Petersen. 1988. "Financing Constraints and Corporate Investment." Brookings Papers on Economic Activity, 19(1): 141-206.

Garrett, Daniel G., Eric Ohrn, and Juan Carlos Suárez Serrato. 2020. "Tax Policy and Local Labor Market Behavior." American Economic Review: Insights, 2(1): $83-100$. 
Gennaioli, Nicola, Yueran Ma, and Andrei Shleifer. 2016. "Expectations and Investment." NBER Macroeconomics Annual, 30: 379-431.

Goolsbee, Austan. 2000. "The Importance of Measurement Error in the Cost of Capital." National Tax Journal, 53(2): 215-228.

Guceri, Irem, and Li Liu. 2019. "Effectiveness of Fiscal Incentives for R\&D: Quasiexperimental Evidence." American Economic Journal: Economic Policy, 11(1): 26691.

Guiso, Luigi, and Giuseppe Parigi. 1999. "Investment and Demand Uncertainty." Quarterly Journal of Economics, 114(1): 185-227.

Gulen, H., and M. Ion. 2016. "Policy uncertainty and corporate investment." Review of Financial Studies, 29(3): 523-564. cited By 179.

Hall, Robert E., and Dale W. Jorgenson. 1967. "Tax Policy and Investment Behavior." The American Economic Review, 57(3): pp. 391-414.

Hassett, Kevin A., and R. Glenn Hubbard. 2002. "Chapter 20 - Tax Policy and Business Investment." In . Vol. 3 of Handbook of Public Economics, , ed. Alan J. Auerbach and Martin Feldstein, 1293 - 1343. Elsevier.

Hennessy, Christopher A., and Toni Whited. 2007. "How Costly Is External Financing? Evidence from a Structural Estimation." Journal of Finance, 62(4): 17051745 .

Hoberg, Gerard, and Vojislav Maksimovic. 2015. "Redefining Financial Constraints: A Text-Based Analysis." The Review of Financial Studies, 28(5): 1312-1352.

House, Christopher L., and Matthew D. Shapiro. 2008. "Temporary Investment Tax Incentives: Theory with Evidence from Bonus Depreciation." American Economic Review, 98(3): 737-68.

Hoynes, Hilary, Douglas L. Miller, and Jessamyn Schaller. 2012. "Who Suffers during Recessions?" Journal of Economic Perspectives, 26(3): 27-48.

Ilzetzki, Ethan, Enrique G. Mendoza, and Carlos A. Vegh. 2013. "How big (small?) are fiscal multipliers?" Journal of Monetary Economics, 60(2): 239 - 254.

Ivashina, Victoria, and David Scharfstein. 2010. "Bank lending during the financial crisis of 2008." Journal of Financial Economics, 97(3): 319 - 338. The 2007-8 financial crisis: Lessons from corporate finance. 
Jens, Candace E. 2017. "Political uncertainty and investment: Causal evidence from U.S. gubernatorial elections." Journal of Financial Economics, 124(3): 563-579.

Jorgenson, Dale W. 1963. "Capital Theory and Investment Behavior." The American Economic Review, 53(2): pp. 247-259.

Jurado, Kyle, Sydney C. Ludvigson, and Serena Ng. 2015. "Measuring Uncertainty." American Economic Review, 105(3): 1177-1216.

Kitchen, John, and Matthew Knittel. 2016. "Business Use of Section 179 Expensing and Bonus Depreciation, 2002-2014." US Department of Treasury Office of Tax Analysis Working Paper 110.

Leahy, John, and Toni Whited. 1996. "The Effect of Uncertainty on Investment: Some Stylized Facts." Journal of Money, Credit and Banking, 28(1): 64-83.

Liu, Li, Benjamin Lockwood, Miguel Almunia, and Eddy H.F. Tam. 2018. "VAT Notches, Voluntary Registration, and Bunching: Theory and UK Evidence." Working Paper.

Maffini, Giorgia, Jing Xing, and Michael P. Devereux. 2019. "The Impact of Investment Incentives: Evidence from UK Corporation Tax Returns." American Economic Journal: Economic Policy, 11(3): 361-89.

Mineshima, Aiko, Marcos Poplawski-Ribeiro, and Anke Weber. 2014. "Size of Fiscal Multipliers." Post-crisis Fiscal Policy, , ed. Carlo Cottarelli, Philip Gerson and Abdelhak Senhadji. The MIT Press.

Moyen, Nathalie. 2004. "Investment-Cash Flow Sensitivities: Constrained versus Unconstrained Firms." The Journal of Finance, 59(5): 2061-2092.

Nilsen, Øivind, and Fabio Schiantarelli. 2003. "Zeros and Lumps in Investment: Empirical Evidence on Irreversibilities and Nonconvexities." Review of Economics and Statistics, 85(4): 1021-1037.

Ohrn, Eric. 2018. "The effect of corporate taxation on investment and financial policy." American Economic Journal: Economic Policy, 2: 272-301.

Ramey, Valerie A. 2019. "Ten Years after the Financial Crisis: What Have We Learned from the Renaissance in Fiscal Research?" Journal of Economic Perspectives, 33(2): 89-114. 
Segal, Gill, Ivan Shaliastovich, and Amir Yaron. 2015. "Good and bad uncertainty: Macroeconomic and financial market implications." Journal of Financial Economics, 117(2): 369-397.

Strebulaev, Ilya A., and Toni M. Whited. 2012. "Dynamic Models and Structural Estimation in Corporate Finance." Foundations and Trends(R) in Finance, 6(1?2): 1163.

Whited, Toni. 2006. "External Finance Constraints and the Intertemporal Pattern of Intermittent Investment." Journal of Financial Economics, 81: 467-502.

Whited, Toni M. 1992. "Debt, Liquidity Constraints, and Corporate Investment: Evidence from Panel Data." The Journal of Finance, 47(4): 1425-1460.

Winberry, Thomas. 2018. "Lumpy Investment, Business Cycles and Stimulus Policy." mimeo.

Zeira, Joseph. 1987. "Investment as a Process of Search." Journal of Political Economy, 95(1): 204-10.

Zwick, Eric, and James Mahon. 2017. "Tax Policy and Heterogeneous Investment Behavior." American Economic Review, 107(1): 217-248. 


\section{Figures}

Figure 1. Reform timeline, 2007-2011

$\begin{array}{ccccccc}\text { PLN } & 3,180,000 & 3,014,000 & 2,702,000 & 5,067,000 & 4,736,000 & 5,324,000 \\ & 2007 & 2008 & 2009 & 2010 & 2011 & 2012 \\ \text { EUR } & 800,000 & 800,000 & 800,000 & 1,200,000 & 1,200,000 & 1,200,000\end{array}$

Note: This timeline shows the turnover thresholds that determine treated firms. For firms to benefit from the policy in each year $t$ in this timeline, their turnover value in year $t-1$ must remain below the Euro-denominated threshold for the firm to benefit from the policy for its investment year $t$. The statutory revenue limits must be set at Euro values for conformity with the EU State Aid requirements. Exchange rate for conversion is the National Bank of Poland reference rate on 1 October of year $t-1$. The Euro-denominated increase in the threshold from 800,000 Euros to 1,200,000 Euros took place in the middle of year 2009. We remove this year from our analysis and verify that treatment assignment was not affected by the mid-year introduction of the policy.

Figure 2. Treatment and control categories for the two samples

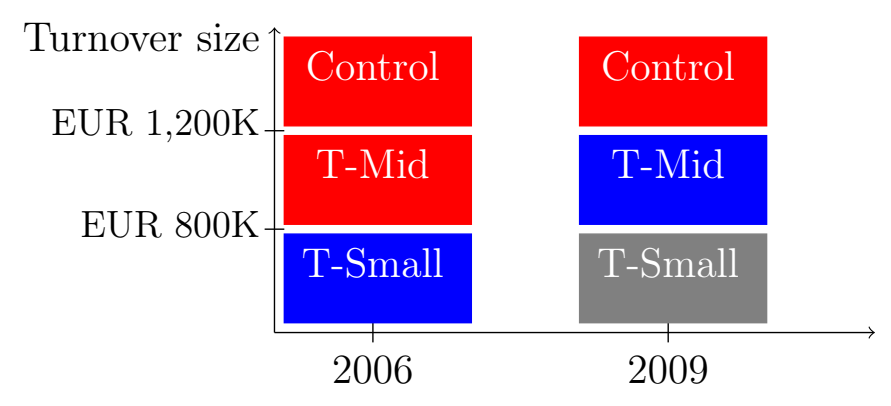


Figure 3. Number of firms by size bins relative to the turnover threshold in period $t-1$ for eligibility to the policy in period $t$
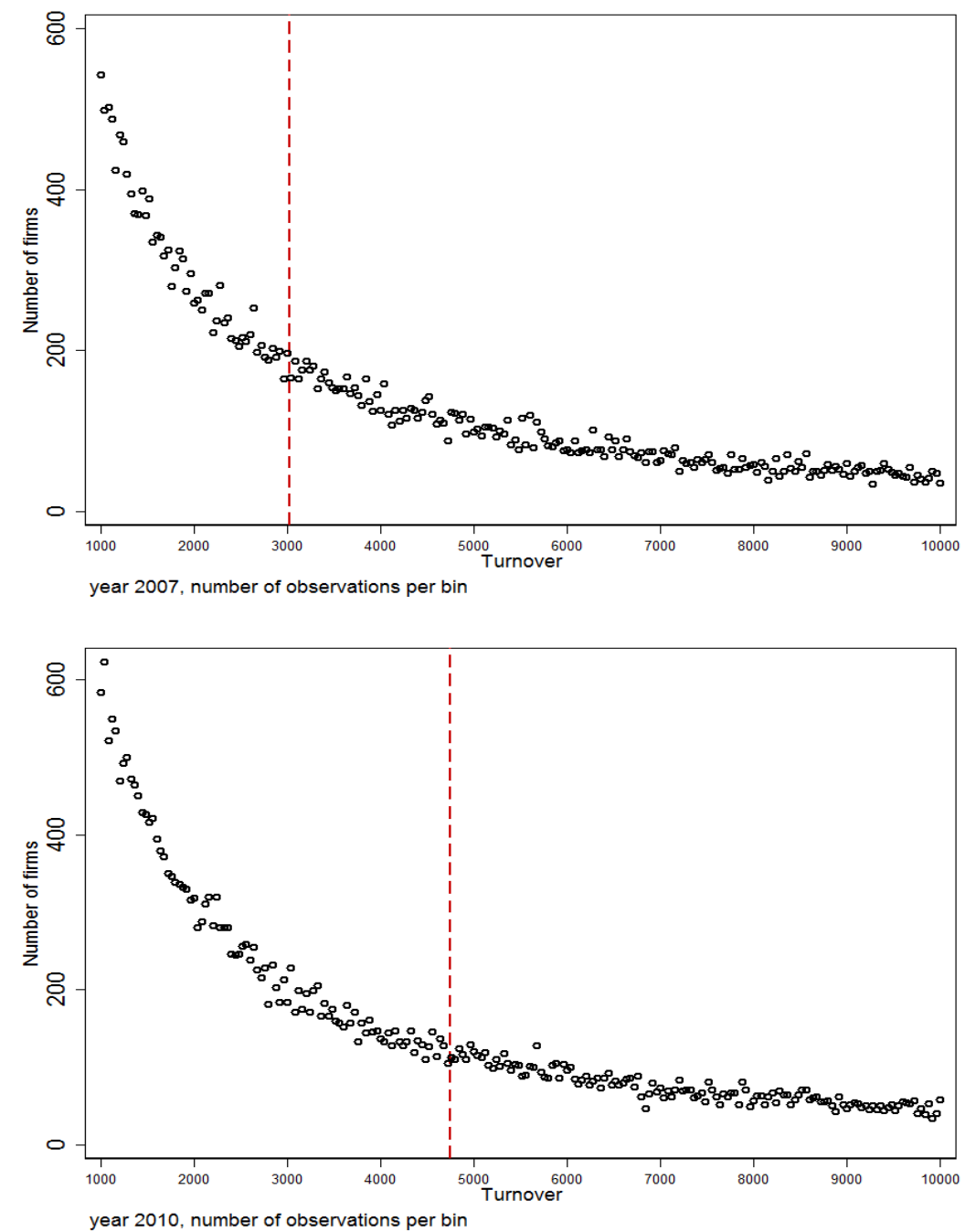

Note: The two graphs show the number of firms in each 40,000-Zloty turnover bin in the first postreform year, based on the firms' turnover values from previous year. The red dotted lines show the turnover threshold for the given period. Hollow circles represent the number of firms in the bin corresponding to the turnover value indicated in the $\mathrm{x}$-axis. 
Figure 4. Volatility at the firm level

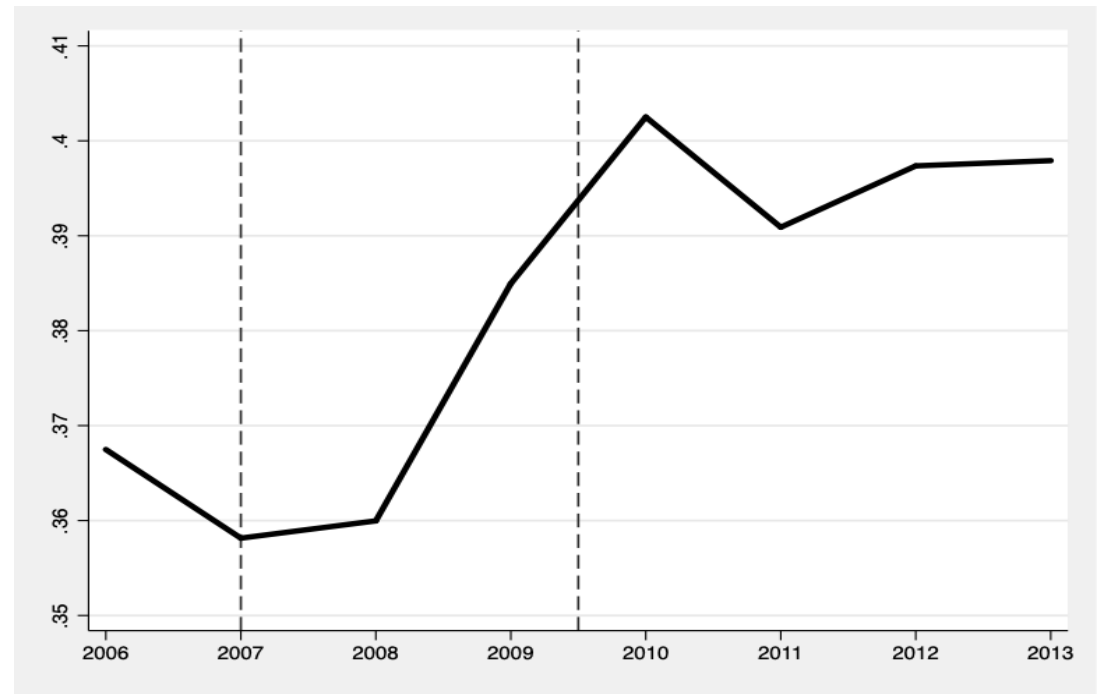

Note: The graph demonstrates a turnover-based volatility measure in the spirit of Bloom et al. (2018) at its annual median values for the population of corporation tax returns in Poland which is available at monthly frequency. To construct the volatility indicator, we take the year-on-year rate of growth of turnover for each month of the year, then take the standard deviation of this variable for each firm-year pair. 
Figure 5. Evolution of first-moment measures, by exposure to uncertainty

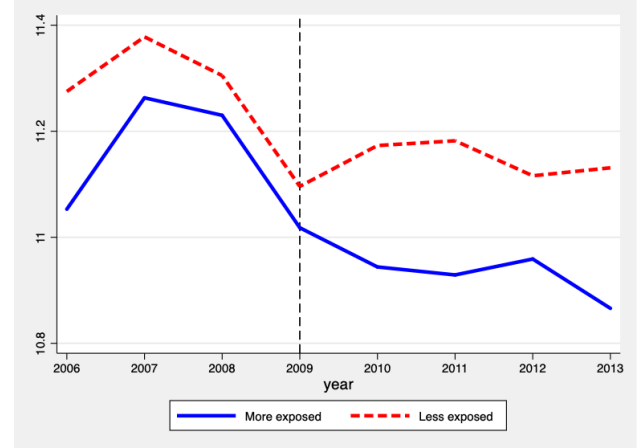

(a) Average investment (in log)

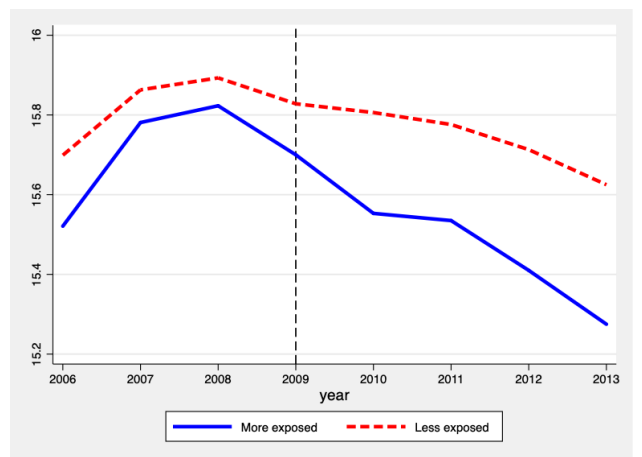

(c) Average turnover (in log)

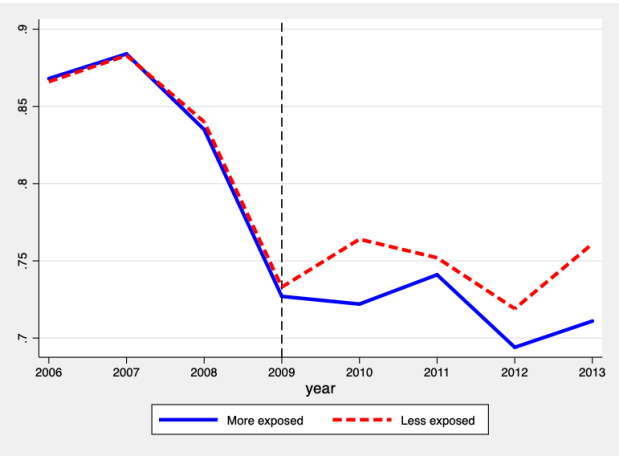

(b) Share of profitable companies

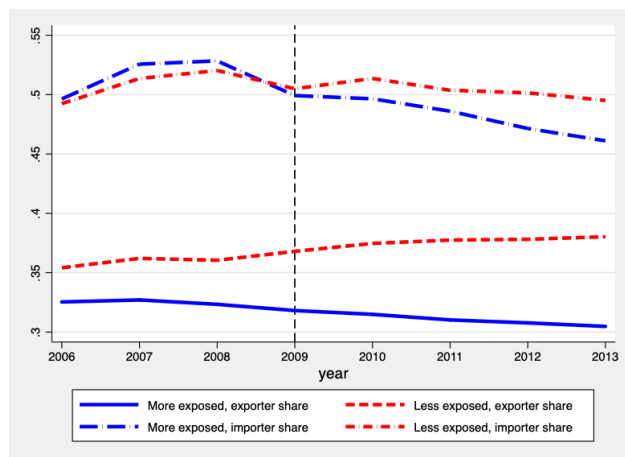

(d) Shares of exporters and importers

Note: Split by exposure to uncertainty, Panel (a) shows the average investment (in log), Panel (b) shows the share of companies that report taxable profit, Panel (c) shows the average turnover (in log), and Panel (d) shows the shares of exporters and importers in each of the more exposed and the less exposed groups. The straight blue line captures the trends for firms more exposed to uncertainty, and the dashed red line captures the trends for firms that are relatively sheltered from uncertainty. In Panel (d), the importer shares for the more exposed group are captured by the blue lines with the long dashdot pattern, and the importer shares for the less exposed group are captured by the red lines with the short dash-dot pattern. 
Figure 6. Distribution of firms across broad sectors, by exposure to uncertainty

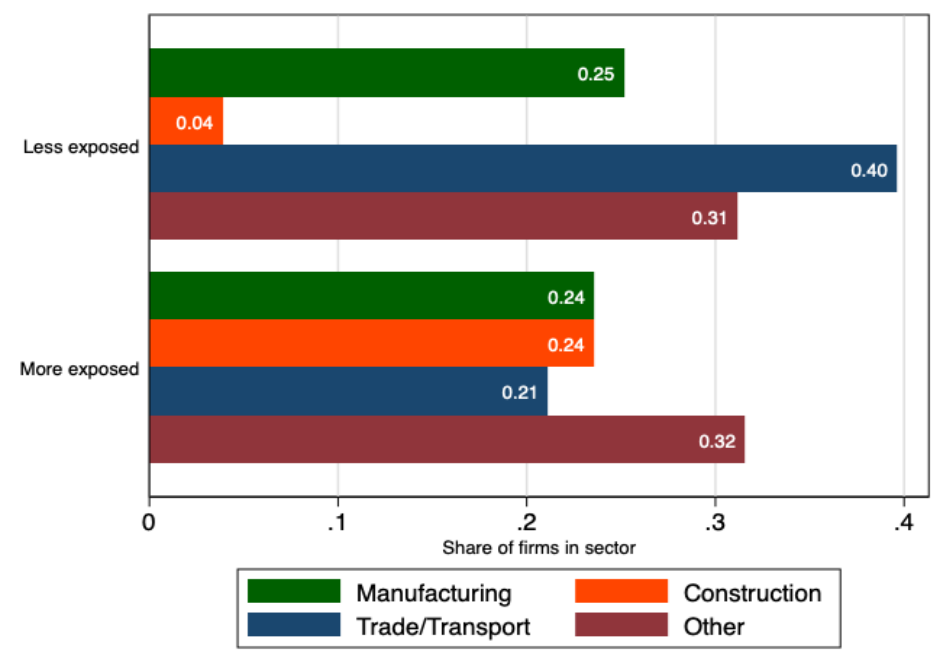

Note: Split by exposure to uncertainty, the top four bars in the graph show the share of 'manufacturing', 'construction', 'trade/transport', and 'other' sectors' shares in the 'more exposed' category, and the bottom four bars show the share of each sector in the 'less exposed' category. The proportions sum to one within each of the 'more exposed' and the 'less exposed' groups.

Figure 7. Trends in average investment across groups, low volatility period

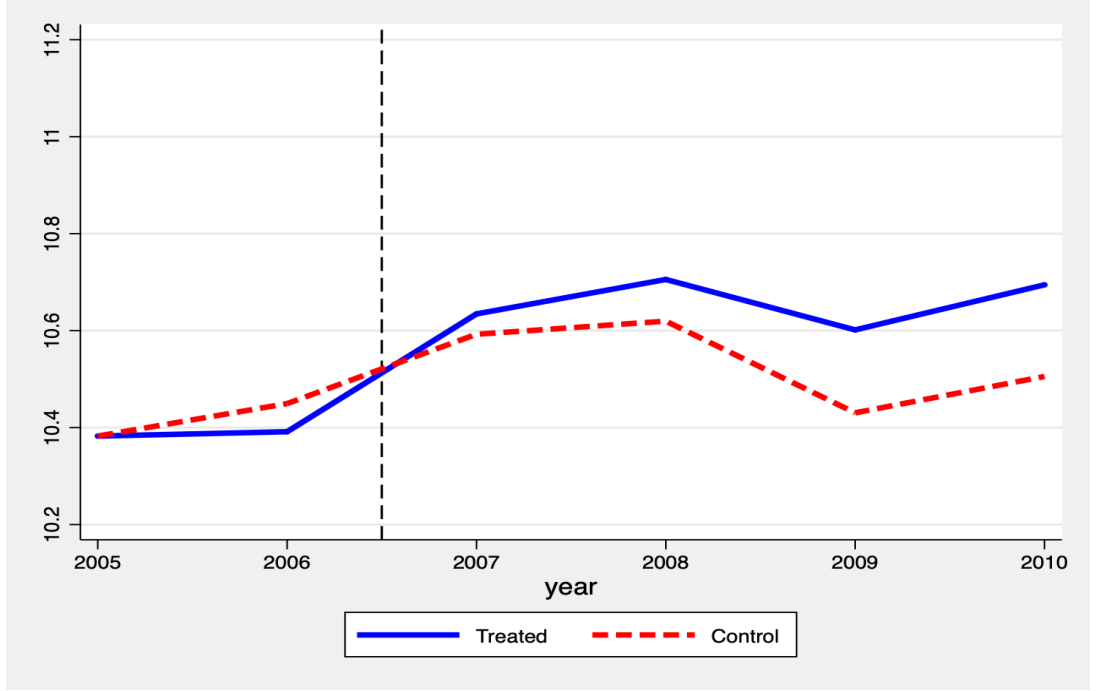

Note: This graph plots the raw means of average investment (in log) by treated and control groups. The reform applies to all treated firms starting from the beginning of 2007. For comparability, we subtract from each data point the group mean for 2005 and add back the pooled mean from the same period. The vertical gray dashed line marks the last pre-reform period. 
Figure 8. Trends in average investment across groups, high volatility period

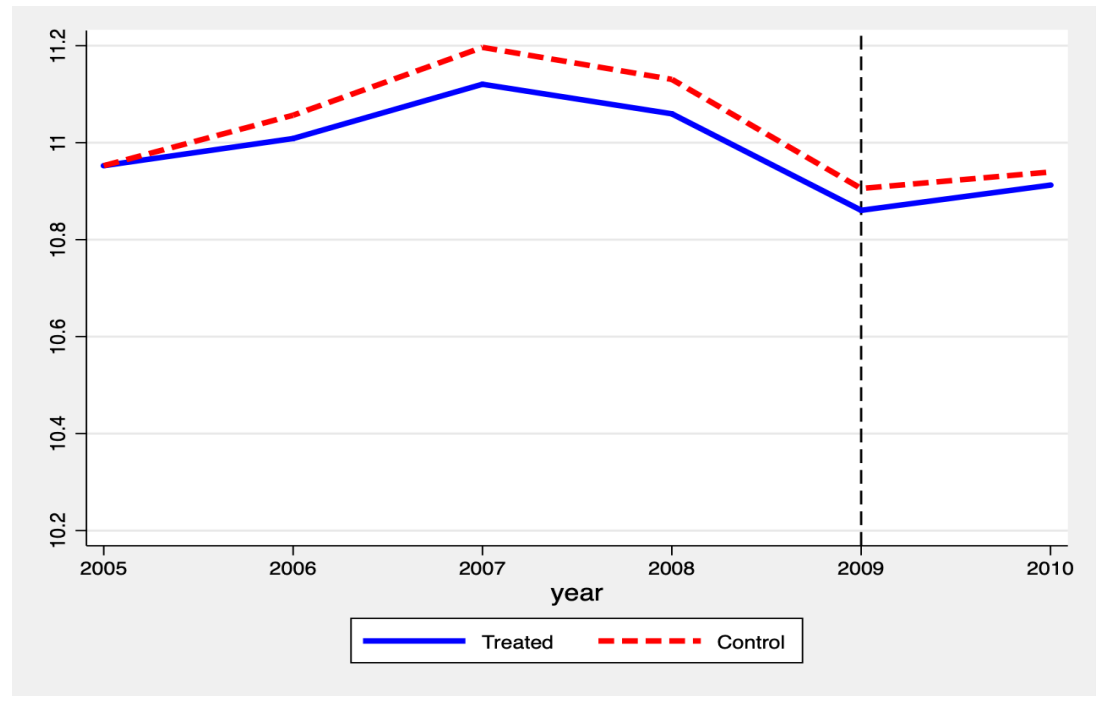

Note: This graph plots the raw means of average investment (in log) by treated and control groups. The reform was implemented in the middle of 2009. For comparability, we subtract from each data point the group mean for the first year and add back the pooled mean from the same period. The vertical gray dashed line marks the last pre-reform period. This sample excludes firms that were treated in 2008 based on 2007 turnover, ruling out large jumps from small to medium size. To reduce the risk that the treated group in the second experiment is populated by shrinking businesses (i.e. mid-sized firms in 2007 that became small in 2009), we impose a restriction on turnover change. Firms are excluded from the second experiment if their turnover changed between 2007 and 2009 by more than $40 \%$. We use an analogous condition for first experiment, with regard to change in turnover between 2005 and 2006.

Figure 9. Trends in average investment across groups, 2006-2007 sample, quarterly

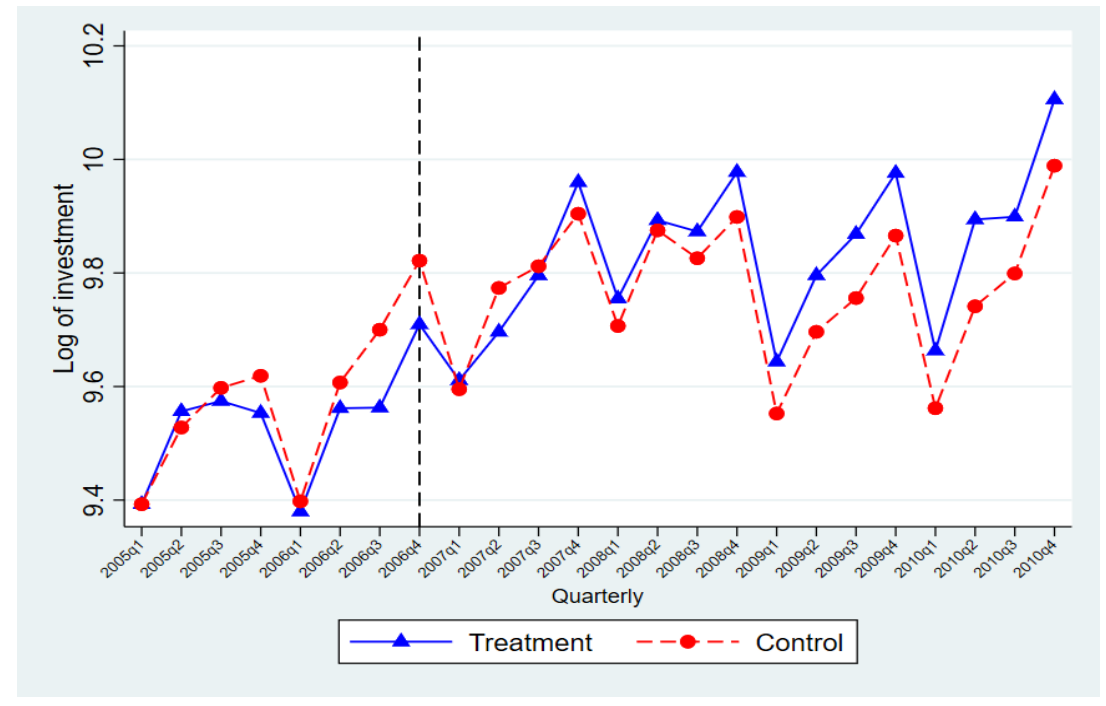

Note: This graph plots the average investment (in log) series for the treatment and control groups in the sample that we use to evaluate the Experiment 1, which covers years 2006 and 2007. For comparability, we subtract from each data point the group mean from 2005Q1 and add back the pooled mean from the same period. The vertical black-dashed line marks the last pre-reform period. 
Figure 10. Trends in average investment across groups, 2008-2010 sample, quarterly

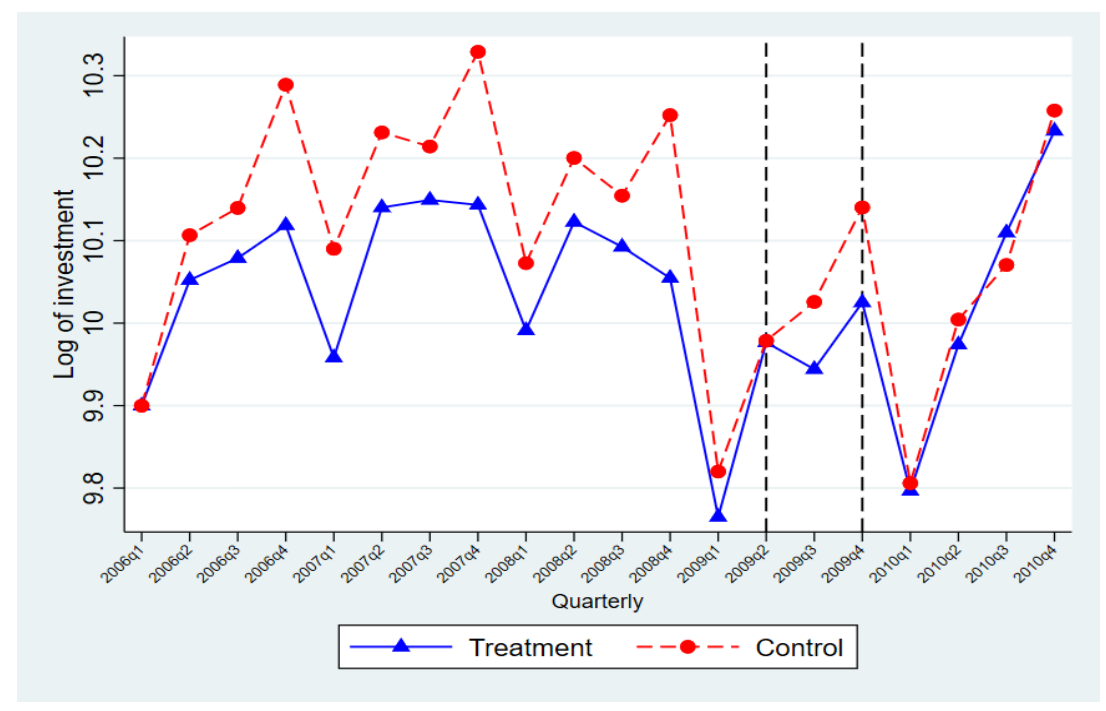

Note: This graph plots the average investment (in log) series for the treatment and control groups in the sample that we use to evaluate Experiment 2, which covers years 2008 and 2010. For comparability, we subtract from each data point the group mean from 2006Q1 and add back the pooled mean from the same period. The vertical black-dashed line marks the pre-reform periods.

Figure 11. Economic sentiment, 2005-2012

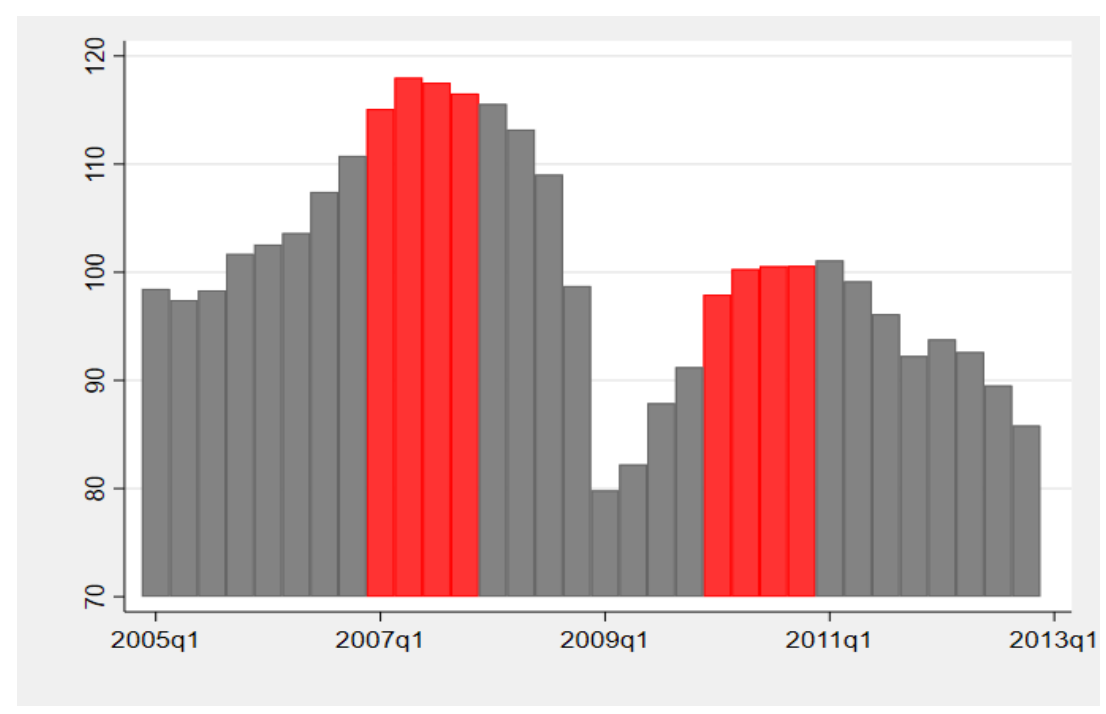

Note: Economic Sentiment Indicator is computed by Eurostat based on five sectoral confidence indicators. Red bars represent the two treatment periods analysed in the paper: 2007 and 2010. Additional details about the construction of the index, its components and historic values are publicly available at: https://ec.europa.eu/eurostat/web/products-datasets/-/teibs010. 
Figure 12. Effects of economic conditions in post-2009 by different size groups

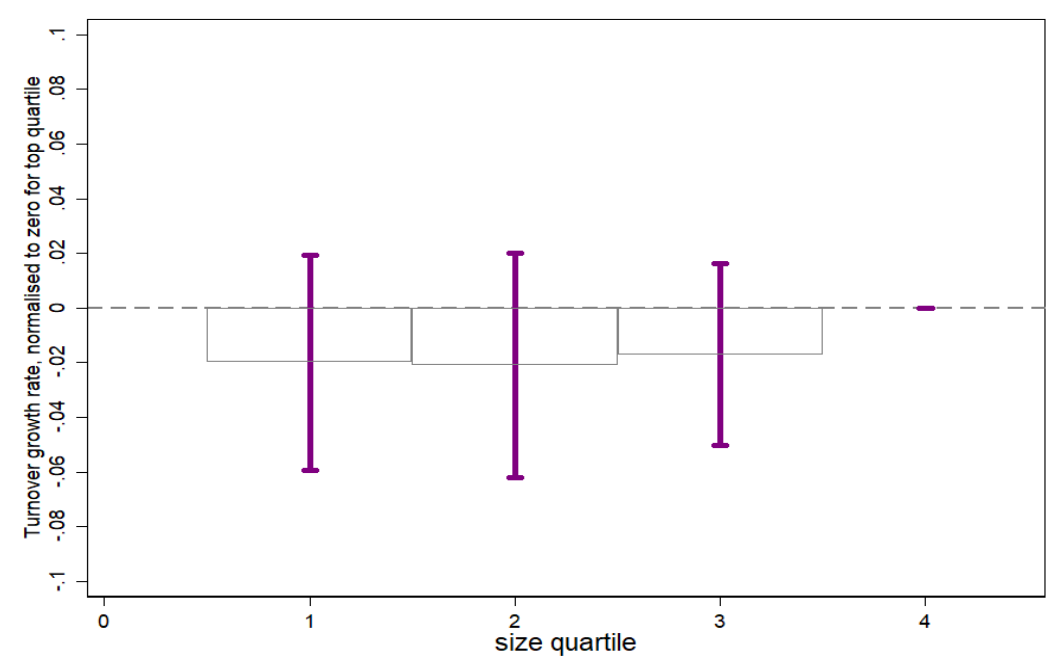

Note: This figure shows how the different size categories were affected by the global liquidity crisis and the currency depreciation in Poland. We drop all treated firms and restrict analysis to control firms. Data years included in the regressions in this table are 2008 and 2010. Within the control group, we identify four size quartiles based on turnover values in our reference year for Experiment 2. We assign a dummy variable for each of the groups, then interact this dummy variable with a post-2009 dummy. We normalise the largest quartile to zero, and run an OLS on within-transformed data to remove company fixed effects. The outcome variable of interest is the log of the turnover growth rate. The coefficients of interest are the size groups interacted with the post-2009 dummy. We include year effects, sector-year, importer/exporter-year interactions as controls. 
Figure 13. Credit conditions by different firm size categories

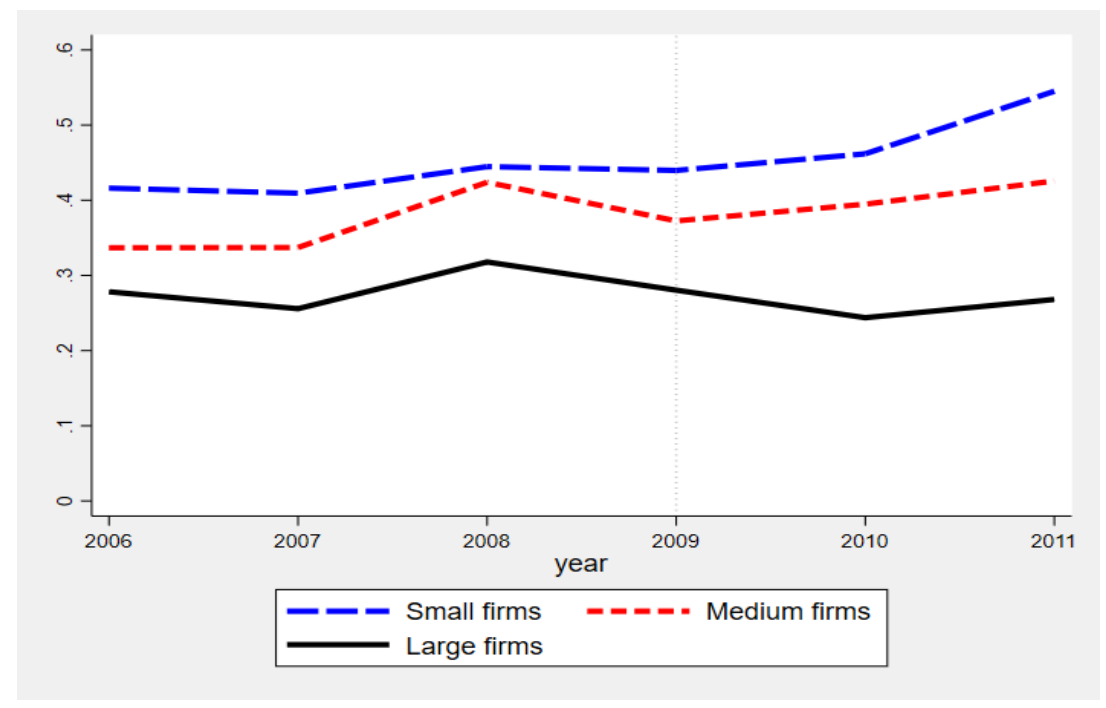

Note: This graph shows the Debt-to-Tangible Net Worth ratio for different firm size groups. We use data from Statistics Poland's publicly available aggregate tables on company balance sheets in 'Table 35: Selected assets, equities and liabilities by the number of employed persons'. The 'small' category consists of companies employing below 50 employees, the 'medium' category consists of companies employing between 50 and 249 employees, and the 'large' category consists of companies employing more than 249 employees. We calculate the Debt-to-TNW ratio as: (Short term credit and loans + Long term credit and loans) / (Shareholders' equity - Intangible assets) 


\section{TABLES}

Table 1. Transitions between treatment and control status, from Experiment 1 to 2

\begin{tabular}{lcccc}
\hline & $\begin{array}{c}\text { Treated in } \\
\text { Experiment 2 }\end{array}$ & $\begin{array}{c}\text { Control in } \\
\text { Experiment 2 }\end{array}$ & $\begin{array}{c}\text { Excluded from } \\
\text { Experiment 2 }\end{array}$ & Total \\
\hline Treated in Experiment 1 & $4 \%$ & $1 \%$ & $95 \%$ & $100 \%$ \\
Control in Experiment 1 & $17 \%$ & $45 \%$ & $38 \%$ & $100 \%$ \\
\hline
\end{tabular}

Note: This table shows the transitions from Experiment 1 to Experiment 2, in terms of percentages of firms in the treated and control groups of Experiment 1.

Table 2. Summary Statistics

\begin{tabular}{|c|c|c|c|c|c|c|c|c|c|}
\hline & $\begin{array}{l}\text { No of } \\
\text { firms }\end{array}$ & $\begin{array}{l}\text { Share } \\
\text { invest }\end{array}$ & $\begin{array}{l}\text { Share } \\
\text { import }\end{array}$ & $\begin{array}{l}\text { Share } \\
\text { export }\end{array}$ & $\begin{array}{l}\text { Mean } \\
\text { invest. }\end{array}$ & $\begin{array}{l}\text { Mean } \\
\text { turn. }\end{array}$ & $\begin{array}{c}\text { Mean } \\
\text { exports }\end{array}$ & $\begin{array}{c}\text { Mean } \\
\text { imports }\end{array}$ & $\begin{array}{l}\text { Mean } \\
\text { age }\end{array}$ \\
\hline & \multicolumn{9}{|c|}{ The 'Low Volatility Period', data for 2006} \\
\hline All sectors & 21008 & 0.56 & 0.32 & 0.22 & 110 & 3,490 & 220 & 287 & 10.2 \\
\hline Manufacturing & 3786 & 0.66 & 0.54 & 0.53 & 155 & 4,147 & 756 & 391 & 10.5 \\
\hline Construction & 1670 & 0.58 & 0.19 & 0.08 & 71 & 3,638 & 37 & 85 & 11.4 \\
\hline Trade \& transport & 5424 & 0.54 & 0.46 & 0.30 & 61 & 4,041 & 161 & 637 & 9.6 \\
\hline \multirow[t]{2}{*}{ Others } & 10128 & 0.53 & 0.19 & 0.09 & 127 & 2,924 & 82 & 93 & 10.2 \\
\hline & \multicolumn{9}{|c|}{ The 'High Volatility Period', data for 2009} \\
\hline All sectors & 10,755 & 0.72 & 0.50 & 0.35 & 264 & 8,188 & 581 & 747 & 11.8 \\
\hline Manufacturing & 2,637 & 0.80 & 0.74 & 0.68 & 289 & 8,338 & 1,638 & 860 & 12.2 \\
\hline Construction & 1,030 & 0.72 & 0.28 & 0.09 & 163 & 8,007 & 43 & 160 & 12.4 \\
\hline Trade \& transport & 3,667 & 0.66 & 0.56 & 0.39 & 128 & 8,492 & 340 & 1,330 & 10.9 \\
\hline Others & 3,421 & 0.72 & 0.33 & 0.15 & 421 & 7,800 & 186 & 211 & 12.2 \\
\hline
\end{tabular}

Note: Turnover, investment, export and import values are in nominal, thousand PLN. In the table, we present the statistics for the last pre-reform period for the treatment and control samples that are used in estimation. Mean values of investment, imports and exports are based on all firms belonging to a sample, including zeros values of these variables. 
Table 3. Baseline results, low volatility period

\begin{tabular}{lllll}
\hline \hline Dep.var: log(investment) & $(1)$ & $(2)$ & $(3)$ & $(4)$ \\
\hline Treated × Post 2006 & $0.077^{* *}$ & $0.081^{* *}$ & $0.089^{* *}$ & $0.083^{* *}$ \\
& $(0.037)$ & $(0.038)$ & $(0.038)$ & $(0.038)$ \\
\hline & & & & \\
Turnover control (lag, in log)? & Yes & Yes & Yes & Yes \\
Turnover control (lag, quart. dum.)? & No & Yes & Yes & Yes \\
Firm fixed effects? & Yes & Yes & Yes & Yes \\
Year effects? & Yes & Yes & Yes & Yes \\
Sector-year effects? & No & No & Yes & Yes \\
Exporter-year effects? & No & No & No & Yes \\
Importer-year effects? & No & No & No & Yes \\
& & & & \\
\hline No of observations & 23222 & 23222 & 23222 & 23222 \\
No of treated firms & 5499 & 5499 & 5499 & 5499 \\
No of control firms & 6260 & 6260 & 6260 & 6260 \\
\hline
\end{tabular}

Note: In this table, we present our baseline estimates for the specification with log(investment) as the dependent variable. The analysis period covered in this table is 2006-2007. We estimate the specification in Equation 1 using ordinary least squares on the within-transformed model to remove the firm fixed effects. In Column (1), we include year dummies and a control for the time-varying turnover variable. In an attempt to more flexibly model the effect of firm size, in Column (2), we also include dummy variables to capture the size quartile based on lagged turnover. In Column (3), we add sector-year dummies to control for sector-specific time trends. In Column (4), we include firm-specific export and import shares in turnover interacted by year which separately capture the time-varying changes experienced by exporters and importers, based on their turnover shares in these activities in the last pre-reform period. Standard errors are clustered at the company level. 
Table 4. Baseline results, high volatility period

\begin{tabular}{|c|c|c|c|c|c|c|c|}
\hline $\begin{array}{l}\text { Specification: } \\
\text { Dep.var: }\end{array}$ & $\begin{array}{l}\text { Eq.(1) } \\
\log I_{t} \\
(1)\end{array}$ & $\begin{array}{l}\text { Eq.(1) } \\
\log I_{t} \\
(2)\end{array}$ & $\begin{array}{l}\text { Eq.(1) } \\
\log I_{t} \\
(3)\end{array}$ & $\begin{array}{l}\text { Eq.(1) } \\
\log I_{t} \\
(4)\end{array}$ & $\begin{array}{l}\text { Eq.(1), IV } \\
\log I_{t} \\
(5)\end{array}$ & $\begin{array}{l}\text { Eq.(2) } \\
\log I_{t} \\
(6)\end{array}$ & $\begin{array}{l}\text { Poisson } \\
I_{t} \\
(7) \\
\end{array}$ \\
\hline Treated $\times$ Post 2009 & $\begin{array}{l}0.088 \\
(0.059)\end{array}$ & $\begin{array}{l}0.060 \\
(0.059)\end{array}$ & $\begin{array}{l}0.070 \\
(0.059)\end{array}$ & $\begin{array}{l}0.064 \\
(0.059)\end{array}$ & $\begin{array}{l}0.020 \\
(0.088)\end{array}$ & $\begin{array}{l}0.122^{*} \\
(0.070)\end{array}$ & $\begin{array}{l}0.243^{* * *} \\
(0.061)\end{array}$ \\
\hline Treated $\times$ Post $2009 \times$ High Exposure & & & & & & $\begin{array}{l}-0.159 \\
(0.128)\end{array}$ & $\begin{array}{l}-0.239^{* *} \\
(0.110)\end{array}$ \\
\hline Post $2009 \times$ High Exposure & & & & & & $\begin{array}{l}-0.080 \\
(0.066) \\
\end{array}$ & $\begin{array}{l}0.003 \\
(0.048) \\
\end{array}$ \\
\hline Turnover control (lag, in log)? & Yes & Yes & Yes & Yes & Yes & Yes & Yes \\
\hline Turnover control (lag, quart. dum.)? & No & Yes & Yes & Yes & Yes & Yes & Yes \\
\hline Firm fixed effects? & Yes & Yes & Yes & Yes & Yes & Yes & Yes \\
\hline Year effects? & Yes & Yes & Yes & Yes & Yes & Yes & Yes \\
\hline Sector-year effects? & No & No & Yes & Yes & Yes & Yes & No \\
\hline Exporter/Importer-year effects? & No & No & No & Yes & Yes & Yes & No \\
\hline Exporter/Importer cont.? & No & No & No & No & No & No & Yes \\
\hline No of observations & 15779 & 15779 & 15779 & 15779 & 15773 & 15777 & 18006 \\
\hline No of treated firms & 1984 & 1984 & 1984 & 1984 & 1984 & 1984 & 2533 \\
\hline No of control firms & 5601 & 5601 & 5601 & 5601 & 5601 & 5600 & 6470 \\
\hline $\begin{array}{l}\text { p-val. Coeff. on Treated } \times \text { Post } 2009 \\
=\text { Coeff. on Treated } \times \text { Post } 2006 \\
\text { p-val. Coeff. on Treated } \times \text { Post } 2009 \times \\
+ \text { Coeff. on Treated } \times \text { Post } 2009=0 \\
\end{array}$ & 0.878 & 0.759 & 0.791 & 0.796 & & 0.739 & 0.963 \\
\hline
\end{tabular}

Note: In this table, we present our baseline estimates for the specification with log(investment) as the dependent variable. The analysis period covered in this table is 2008-2010. Standard errors are clustered at the company level. We estimate the specification in Equation 1 using ordinary least squares on the within-transformed model to remove the firm fixed effects. In Column (1), we include year dummies and a control for the time-varying turnover variable. In an attempt to more flexibly model the effect of firm size, in Column (2), we also include dummy variables to capture the size quartile based on lagged turnover. In Column (3), we add sector-year dummies to control for sector-specific time trends. In Column (4), we include firm-specific export and import shares in turnover interacted by year which separately capture the time-varying changes experienced by exporters and importers, based on their turnover shares in these activities in the last pre-reform period. In Columns (1)-(4), we report the $p$-value for the test of the null hypothesis that the coefficient of Treated $\times$ Post 2009 in the high volatility period is equal to the analogous coefficient in the low volatility period. The test is derived from pooled regressions using both samples. In Column (5) we instrument the actual treatment status with a simulated treatment dummy that uses turnover from 2006 rather than the turnover from 2009. In Column (6), we present our estimates for the specification with $\log$ (investment) as the dependent variable, splitting the sample into two groups: high and low exposure to volatility. High exposure firms are those that fall above the median of the exposure distribution in the last pre-reform period. We estimate the preferred specification in the baseline, for which the results are presented in Column (4), additionally interacting the coefficient of interest Treated $\times$ Post 2009 with the dummy variable that captures the effect for firms that have a high exposure to uncertainty in the last pre-reform period. We also interact the 'High Exposure' dummy with 'Post 2009' to take into account the background change in the High Exposure group between the pre-reform and post-reform period that is unrelated to the reform. The coefficient on the uninteracted 'Treated $\times$ Post 2009' variable therefore can be interpreted as the effect of the reform for the firms that had low exposure to uncertainty. We also report the $p$-value for the test of the null hypothesis that the policy effect for the High Exposure group is zero. In Column (7), we use a Poisson regression approach (again with firm fixed effects). In the Poisson regression, extreme values of dependent variable $I_{t}$ in levels is winsorised above the 95 -th percentile value. In Poisson regressions, exporter-year effects and importer-year effects are replaced with lagged imports as a share of firm size and lagged exports as a share of firm size because of difficulties in convergence with many dummy variables. 


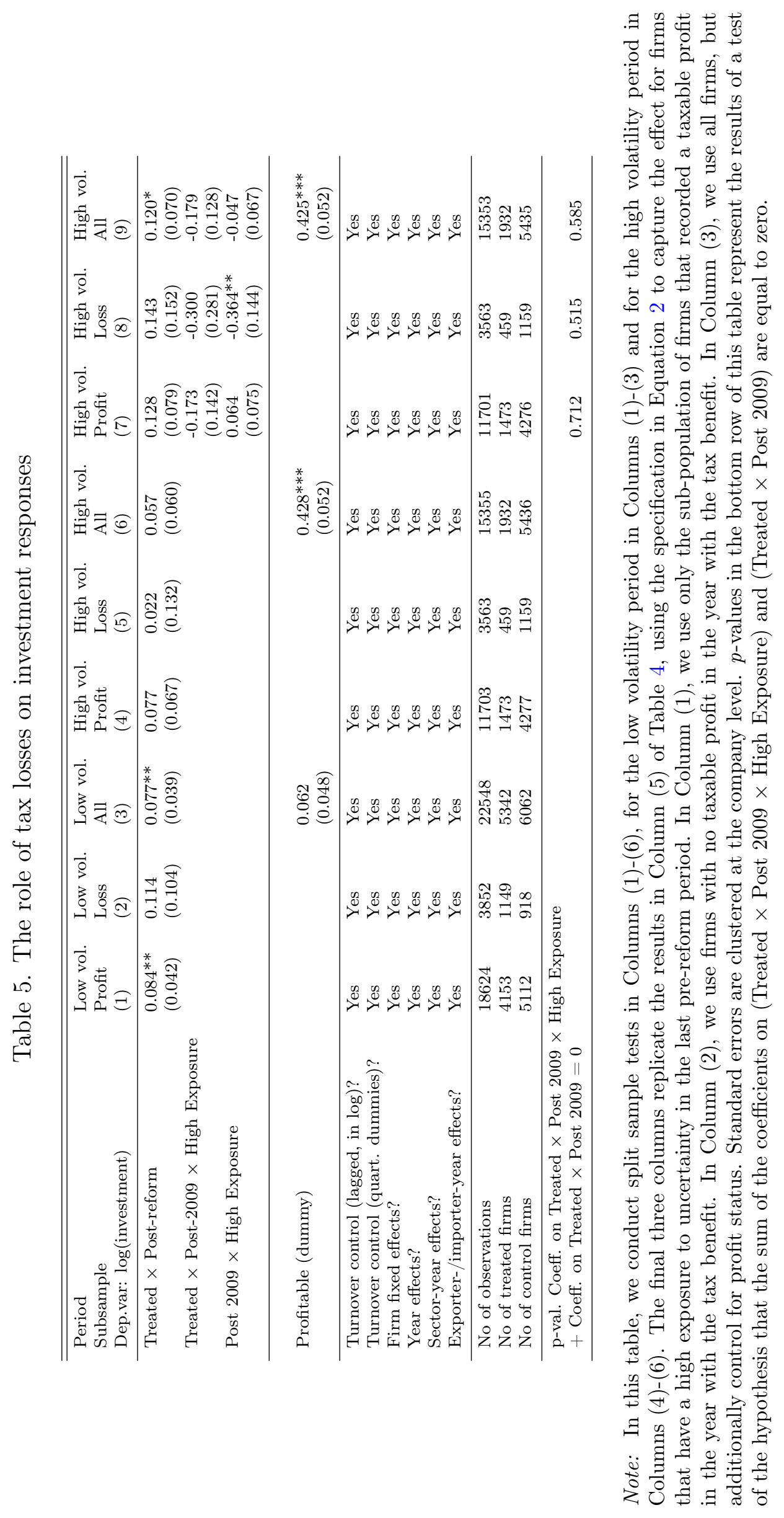


Table 6. Results for pass-through entities

\begin{tabular}{llll}
\hline \hline Specification: & Eq.(1) & Eq. $(1)$ & Eq. $(2)$ \\
Sample period: & Low vol. & High vol. & High vol. \\
Dep.var: $\log ($ investment) & $(1)$ & $(2)$ & $(3)$ \\
\hline Treated $\times$ Post Reform & $0.132^{* * *}$ & 0.018 & 0.039 \\
& $(0.038)$ & $(0.057)$ & $(0.064)$ \\
Treated $\times$ Post $2009 \times$ High Exposure & & -0.094 \\
& & & $(0.139)$ \\
Post 2009 $\times$ High Exposure & & -0.043 \\
& & & $(0.110)$ \\
\hline & & & \\
Turnover control (lag, in log)? & Yes & Yes & Yes \\
Turnover control (lag, quart. dum.)? & No & No & No \\
Firm fixed effects? & Yes & Yes & Yes \\
Year effects? & Yes & Yes & Yes \\
Sector-year effects? & Yes & Yes & Yes \\
Exporter- $/$ importer-year effects? & Yes & Yes & Yes \\
& & & \\
\hline No of observations & 23000 & 12376 & 12260 \\
No of treated firms & 5418 & 2768 & 2737 \\
No of control firms & 6134 & 3220 & 3192 \\
\hline p-val. Coeff. on Treated $\times$ Post 2009 $\times$ High Exposure & 0.660 \\
+ Coeff. on Treated $\times$ Post 2009 $=0$ & & & \\
\hline
\end{tabular}

Note: In this table, we present our baseline estimates for the specification with log(investment) as the dependent variable for unincorporated business from personal income tax returns. There are many more unincorporated small firms than large or medium-sized firms. Therefore, to achieve a degree of comparability, we remove all firms with turnover below 100 thousand PLN. We include all firms above the treatment threshold based on turnover in the last pre-reform period. We then rank the firms below the turnover threshold in descending order and include in the treatment group the same number of firms as in control group. We estimate the specification in Equation 1 using ordinary least squares on the within-transformed model to remove the firm fixed effects. We include year dummies, sectoryear dummies to control for sector-specific time trends, dummy variables which separately capture the importer and exporter statuses in the last pre-reform period and we interact these dummies with year effects. Results in Column (1) use data from the first reform period, results in Column (2) and Column (3) use data from the second reform period. In Column (3), we present our estimates for the specification as in Table 4, additionally interacting the coefficient of interest Treated $\times$ Post 2009 with the dummy variable that captures the effect for firms that have a high exposure to uncertainty in the last prereform period. We also interact the 'High Exposure' dummy with 'Post 2009' to take into account the background change in the High Exposure group between the pre-reform and post-reform period that is unrelated to the reform. The coefficient on the uninteracted 'Treated $\times$ Post 2009' variable therefore can be interpreted as the effect of the reform for the firms that had low exposure to uncertainty. We also report the $p$-value for the test of the null hypothesis that the policy effect for the High Exposure group is zero. The results exclude sole proprietors, for whom we do not have complete information. Standard errors are clustered at the firm level. 
Table 7. Supplementary analyses

\begin{tabular}{|c|c|c|c|c|c|c|c|}
\hline $\begin{array}{r}\text { Sample period } \\
\text { Analysis } \\
\text { Dep.var }\end{array}$ & $\begin{array}{l}\text { Low vol. } \\
\text { Continuous } \\
\text { treatment } \\
\log \left(\mathrm{I}_{t}\right) \\
(1)\end{array}$ & $\begin{array}{l}\text { High vol. } \\
\text { Continuous } \\
\text { treatment } \\
\log \left(\mathrm{I}_{t}\right) \\
(2)\end{array}$ & $\begin{array}{l}\text { Low vol. } \\
\text { Continuous } \\
\text { treatment } \\
\log \left(\mathrm{I}_{t}\right) \\
(3)\end{array}$ & $\begin{array}{l}\text { High vol. } \\
\text { Continuous } \\
\text { treatment } \\
\log \left(\mathrm{I}_{t}\right) \\
(4)\end{array}$ & $\begin{array}{l}\text { Low vol. } \\
\text { Extensive } \\
\text { margin, logit } \\
\mathbb{1}\left(\mathrm{I}_{t}>0\right) \\
(5)\end{array}$ & $\begin{array}{l}\text { High vol. } \\
\text { Extensive } \\
\text { margin, logit } \\
\mathbb{1}\left(\mathrm{I}_{t}>0\right) \\
(6)\end{array}$ & $\begin{array}{l}\text { High vol. } \\
\text { Extensive } \\
\text { margin, logit } \\
\mathbb{1}\left(\mathrm{I}_{t}>0\right) \\
(7)\end{array}$ \\
\hline $\ln ($ user cost $)$ & $\begin{array}{l}-5.193^{* *} \\
(2.054)\end{array}$ & $\begin{array}{l}-3.736 \\
(2.946)\end{array}$ & & & & & \\
\hline$z_{t}$ & & & & $\begin{array}{l}0.821 \\
(0.654)\end{array}$ & & & \\
\hline Treated $\times$ Post Reform & & & & & $\begin{array}{l}0.272^{* * *} \\
(0.063)\end{array}$ & $\begin{array}{l}0.171^{*} \\
(0.093)\end{array}$ & $\begin{array}{l}0.245^{* *} \\
(0.110)\end{array}$ \\
\hline \multicolumn{5}{|l|}{ Treated $\times$ Post $2009 \times$ High Exposure } & & & $\begin{array}{l}-0.232 \\
(0.197)\end{array}$ \\
\hline Post $2009 \times$ High Exposure & & & & & & & $\begin{array}{l}-0.228^{*} \\
(0.129)\end{array}$ \\
\hline Turnover control (lagged, in log)? & Yes & Yes & Yes & Yes & Yes & Yes & Yes \\
\hline Turnover control (lag, quart. dum)? & Yes & Yes & Yes & Yes & Yes & Yes & Yes \\
\hline Firm fixed effects? & Yes & Yes & Yes & Yes & Yes & Yes & Yes \\
\hline Year effects? & Yes & Yes & Yes & Yes & Yes & Yes & Yes \\
\hline Sector-year effects? & Yes & Yes & Yes & Yes & Yes & Yes & Yes \\
\hline Exporter/importer cont.? & No & No & No & No & Yes & Yes & Yes \\
\hline Exporter-/importer-year effects? & Yes & Yes & Yes & Yes & No & No & No \\
\hline Total no of obs. & 17867 & 13611 & 17867 & 13611 & 9638 & 4542 & 4542 \\
\hline No of treated firms & 3896 & 1663 & 3896 & 1663 & 3266 & 888 & 888 \\
\hline No of control firms & 5076 & 4924 & 5076 & 4924 & 1553 & 1383 & 1383 \\
\hline \multicolumn{5}{|c|}{$\begin{array}{l}\text { p-val. Coeff. on Treated } \times \text { Post } 2009 \times \text { High Exposure } \\
+ \text { Coeff. on Treated } \times \text { Post } 2009=0\end{array}$} & 0.936 & & \\
\hline
\end{tabular}

Note: In this table, we present the results for two separate analyses. The first is the one that examines the regression results from a specification with $\log$ (investment) as the dependent variable and our treatment intensity captured by the sectoral variation in the (log of) the tax component of user cost of capital as the key explanatory variable (along with all our standard controls). Column (1) shows the results for the low volatility period and Column (2) shows the results for the high volatility period. In this specification, we replace the Treatment $\times$ Post-reform dummy with our continuous treatment variable to estimate the elasticity of investment with respect to its user cost, whose tax component is constructed using a weighted average measure of the present discounted value of one dollar of depreciation allowances (as described in Section 2). In calculating the tax component, we use data from Statistics Poland on the breakdown of investment into: (i) structures and buildings; (ii) machinery and equipment; and (iii) transport equipment by two-digit NACE sectors. In this table, we therefore exploit both the introduction of the reform and the sectoral variation in treatment intensity. The sector-year controls capture trends at the broader levels. Columns (3) and (4) replace the continuous treatment measure of the user cost with the net present value of the depreciation allowance $\left(z_{t}\right)$ to separate the effect of the asset useful lives from the impact of tax rates.

In Columns (5), (6) and (7), we present conditional logit results that estimate the effect on the log odds of investing for treated firms relative to control. Column (3) shows results from estimations that use the low volatility period data and Columns (6) and (7) are based on results from estimations that use data from the high volatility period. In Column (7), we replicate the analysis in Table 4, this time with the discrete outcome variable, distinguishing between firms that had a high exposure to volatility and those that did not. Results on intensive margin are obtained with the ordinary least squares, while the extensive margin effects were estimated with conditional logit regressions. In all regressions, standard errors are clustered at the company level. In conditional logit regressions, exporter-year effects and importer-year effects are replaced with lagged imports as a share of firm size and lagged exports as a share of firm size because of difficulties in convergence with many dummy variables. $p$-value in the bottom row of this table represent the results of a test of the hypothesis that the sum of the coefficients on (Treated $\times$ Post $2009 \times$ High Exposure) and (Treated $\times$ Post 2009) is equal to zero. 
Table 8. Placebo test results

\begin{tabular}{|c|c|c|c|c|}
\hline $\begin{array}{r}\text { Sample period } \\
\text { Analysis }\end{array}$ & $\begin{array}{l}\text { Low vol. } \\
\text { Placebo }\end{array}$ & $\begin{array}{l}\text { High vol. } \\
\text { Placebo }\end{array}$ & $\begin{array}{l}\text { Low vol. } \\
\text { Placebo }\end{array}$ & $\begin{array}{l}\text { High vol. } \\
\text { Placebo }\end{array}$ \\
\hline Dep.var & $\begin{array}{l}\log \left(I_{t}\right) \\
(1)\end{array}$ & $\begin{array}{l}\log \left(I_{t}\right) \\
(2)\end{array}$ & $\begin{array}{l}I_{t} \\
(3)\end{array}$ & $\begin{array}{l}I_{t} \\
(4)\end{array}$ \\
\hline Placebo Treated $\times$ Post Reform & $\begin{array}{l}-0.001 \\
(0.046)\end{array}$ & $\begin{array}{l}-0.018 \\
(0.056)\end{array}$ & $\begin{array}{l}-0.010 \\
(0.041)\end{array}$ & $\begin{array}{l}-0.003 \\
(0.044)\end{array}$ \\
\hline Firm fixed effects? & Yes & Yes & Yes & Yes \\
\hline Year effects? & Yes & Yes & Yes & Yes \\
\hline Lagged size quartile dum.? & Yes & Yes & Yes & Yes \\
\hline Sector-year effects? & Yes & Yes & Yes & Yes \\
\hline Exporter-/importer-year effects? & Yes & Yes & Yes & Yes \\
\hline Total no of obs. & 12279 & 11591 & 13802 & 12942 \\
\hline No of treated firms & 2937 & 2735 & 3271 & 3138 \\
\hline No of control firms & 3082 & 2866 & 3630 & 3333 \\
\hline
\end{tabular}

Note: To obtain the placebo samples, we use the last pre-reform period median turnover within all control firms that are included in each of the sub-samples. We label the firms that have less-thanmedian turnover as placebo treated and the firms that have higher-than-median turnover as placebo control. In Columns (1) and (2), we estimate the specification in Equation 1, with $\log$ (investment) as dependent variable, using ordinary least squares on the within-transformed model as in the baseline regressions (Tables 3 and 4). Columns (3) and (4) present results from Poisson regressions with the level of investment as dependent variable. This latter approach estimates the total effect at the intensive and the extensive margins. Columns (1) and (3) use data from the low volatility period and Columns (2) and (4) use data from the high volatility period. In all regressions, standard errors are clustered at the company level. In conditional logit regressions, exporter-year effects and importer-year effects are replaced with lagged imports as a share of firm size and lagged exports as a share of firm size because of difficulties in convergence with many dummy variables. 
Table 9. Investment responses by exposure to terms of trade fluctuations and uncertainty

\begin{tabular}{|c|c|c|c|}
\hline $\begin{array}{l}\text { Sample } \\
\text { Dep.var: } \log \text { (investment) }\end{array}$ & $\begin{array}{l}\text { Baseline, } \\
\text { all controls } \\
\text { (1) }\end{array}$ & $\begin{array}{l}\text { No trade-rel. } \\
\text { controls } \\
(2)\end{array}$ & $\begin{array}{l}\text { Non-traders, } \\
\text { with controls } \\
\text { (3) }\end{array}$ \\
\hline Treated $\times$ Post 2009 & $\begin{array}{l}0.122^{*} \\
(0.070)\end{array}$ & $\begin{array}{l}0.129^{*} \\
(0.070)\end{array}$ & $\begin{array}{l}0.183^{* *} \\
(0.080)\end{array}$ \\
\hline Treated $\times$ Post $2009 \times$ High Exposure & $\begin{array}{l}-0.159 \\
(0.128)\end{array}$ & $\begin{array}{l}-0.162 \\
(0.128)\end{array}$ & $\begin{array}{l}-0.135 \\
(0.146)\end{array}$ \\
\hline Post $2009 \times$ High Exposure & $\begin{array}{l}-0.080 \\
(0.066)\end{array}$ & $\begin{array}{l}-0.087 \\
(0.066)\end{array}$ & $\begin{array}{l}-0.111 \\
(0.080)\end{array}$ \\
\hline $\begin{array}{l}\text { Turnover control (lagged, in log)? } \\
\text { Turnover control (quart. dummies)? } \\
\text { Firm fixed effects? } \\
\text { Year effects? } \\
\text { Sector-year effects? } \\
\text { Exporter-/importer-year effects? }\end{array}$ & $\begin{array}{l}\text { Yes } \\
\text { Yes } \\
\text { Yes } \\
\text { Yes } \\
\text { Yes } \\
\text { Yes }\end{array}$ & $\begin{array}{l}\text { Yes } \\
\text { Yes } \\
\text { Yes } \\
\text { Yes } \\
\text { Yes } \\
\text { No }\end{array}$ & $\begin{array}{l}\text { Yes } \\
\text { Yes } \\
\text { Yes } \\
\text { Yes } \\
\text { Yes } \\
\text { No }\end{array}$ \\
\hline $\begin{array}{l}\text { No of observations } \\
\text { No of treated firms } \\
\text { No of control firms }\end{array}$ & $\begin{array}{l}15777 \\
1984 \\
5600\end{array}$ & $\begin{array}{l}15777 \\
1984 \\
5600\end{array}$ & $\begin{array}{l}11040 \\
1463 \\
3852\end{array}$ \\
\hline $\begin{array}{l}\text { p-val. Coeff. on Treated } \times \text { Post } 2009 \times \\
+ \text { Coeff. on Treated } \times \text { Post } 2009=0\end{array}$ & $\begin{array}{l}\text { High Expos } \\
0.739\end{array}$ & e 0.762 & 0.698 \\
\hline
\end{tabular}

Note: This table shows the impact of changes in terms of trade on the results related to uncertainty. Column (1) shows the Baseline result on responses under uncertainty, as in Table 4, Column (5). Column (2) shows the results for these regressions without the importer- and exporter-year effects. Column (3) shows the results for companies that do not have substantial international trade activity, controlling for other factors than trade. $p$-values in the bottom row of this table represent the results of a test of the hypothesis that the sum of the coefficients on (Treated $\times$ Post $2009 \times$ High Exposure) and (Treated $\times$ Post 2009) are equal to zero for each of the columns. 


\section{ONLINE APPENDIX}

\section{A INFORMATION ON DATA AND CLEANING}

Table A.1 reports the impact of data cleaning procedures on the size of the analysis samples. Around $15 \%$ of the corporations were dropped because we suspect that in one of the years (within the period 2005 - 2016) they made a wrong entry in the VAT return. In our estimation samples, we only include mature firms, i.e. firms that are at least five years old in the post-reform period. Furthermore, to enhance comparisons between the treated and control firms we remove from the sample the largest $50 \%$ of the control group and the smallest $50 \%$ of the treated group, based on firm size in the last pre-reform period. Lastly, to reduce the risk that the treated group in the second experiment is populated by shrinking businesses (i.e. mid-sized firms in 2007 that became small in 2009), we impose a restriction on turnover change. Firms are excluded from the second experiment if their turnover changed between 2007 and 2009 by more than $40 \%$. We use the analogous condition for the first experiment, with regard to change in turnover between 2005 and 2006. The last column of the table refers to the samples used in the main analyses.

Table A.1. Population of firms

\begin{tabular}{|c|c|c|c|c|c|c|c|}
\hline Sample & $\begin{array}{l}\text { Number of } \\
\text { firms }\end{array}$ & $\begin{array}{l}\text { After } \\
\text { dropping } \\
\text { unincor- } \\
\text { porated } \\
\text { businesses }\end{array}$ & $\begin{array}{l}\text { After } \\
\text { dropping } \\
\text { implied } \\
\text { data errors }\end{array}$ & $\begin{array}{l}\text { After drop- } \\
\text { ping firms } \\
\text { treated in } \\
2008\end{array}$ & $\begin{array}{l}\text { After drop- } \\
\text { ping young } \\
\text { firms }\end{array}$ & $\begin{array}{l}\text { After } \\
\text { dropping } \\
\text { smallest } \\
\text { and largest } \\
\text { firms }\end{array}$ & $\begin{array}{l}\text { After drop- } \\
\text { ping firms } \\
\text { with large } \\
\text { turnover } \\
\text { changes }\end{array}$ \\
\hline $2006-2007$ & $1,396,856$ & 107,184 & 91,212 & & 62,453 & 31,227 & 21,008 \\
\hline 2008-2010 & $1,565,077$ & 127,313 & 107,548 & 50,730 & 29,801 & 14,900 & 10,755 \\
\hline
\end{tabular}

Generally, VAT returns are verified by tax inspectors and should be accurate. Nevertheless, we use input VAT tax related to investment, as well as firm's turnover, to detect observations which may be erroneous. Then we drop all observations for firms that record at least one data error.

Some firms are not VAT taxpayers, and therefore they cannot be included in the analysis. Product-based VAT exemption is applicable mainly to financial services, health care and education. Entity-based exemption is available for very small firms below an annual turnover threshold, which remained very low during the period of analysis. ${ }^{21}$

Apart from investment and turnover, the data on international trade also comes from

\footnotetext{
${ }^{21}$ During the analysis period, this exemption threshold never exceeded 150,000 PLN, which is well below the neighborhood of the turnover thresholds that we are using in our quasi-experiment.
} 
VAT returns. The exception is extra-EU import, which is added from the customs data. We also merge the VAT data with CIT to gather data on firms' profits and losses.

Further, we take advantage of the register of economic activity to obtain more information at the firm-level. First, the type of entity is used to drop non-businesses from the VAT data. Second, year of registration allows us to distinguish between start ups and established firms. Third, we use the NACE classification code to define sector dummy variables and the continuous treatment measures. The drawback of the data obtained from the company register is that it only reflects recent information, without tracking the historical changes in the firms' classification.

\section{B Institutional DETAils}

Both reforms that we use for identification in our paper apply to expenditure on plant and machinery. Buildings, cars and intangibles are excluded. This is useful in our context as there may be profit-shifting motives in the case of acquisition of intangible assets. In the VAT returns, firms are obliged to declare the investment amount that is associated with any input VAT. Although it excludes some types of investment such as real estate, it covers most of the fixed assets and intangibles.

The first reform was announced when the policy was finalised and enacted in November 2006. The accelerated depreciation then started applying to investment incurred on or after 1 January 2007. We therefore rule out anticipation effects that could have led firms to postpone investment. The late announcement of the policy is especially important for our classification of firms into treatment and control, because it also meant that firms could not try to manipulate their turnover in 2006. There were no plans or preparation of a second reform, which was adopted to respond to the global economic downturn.

\section{Macroeconomic COnditions DURing The SAMple PERIOD}

The first reform was introduced during a peak in the business cycle. In 2006, the Polish GDP growth exceeded $6 \%$ and corporate investment grew by almost $17 \%$ (Figure A.1). The second reform, on the other hand, was introduced to respond to the global financial crisis. Although Poland avoided recession during the 2008-2009 period, economic growth was significantly dampened. Aggregate corporate investment decreased in 2009 and 2010, each year by around $7 \%$. 
In advanced economies such as the US and the UK, bank lending dropped substantially in the global liquidity crisis (Ivashina and Scharfstein, 2010). In Poland, partly thanks to a less developed financial system in the pre-crisis period, bank lending did not suffer from the global credit crunch to the same extent as in most advanced economies (Drozdowicz-Biec, 2011).

Figure A.1. Macroeconomic developments, 2000-2012

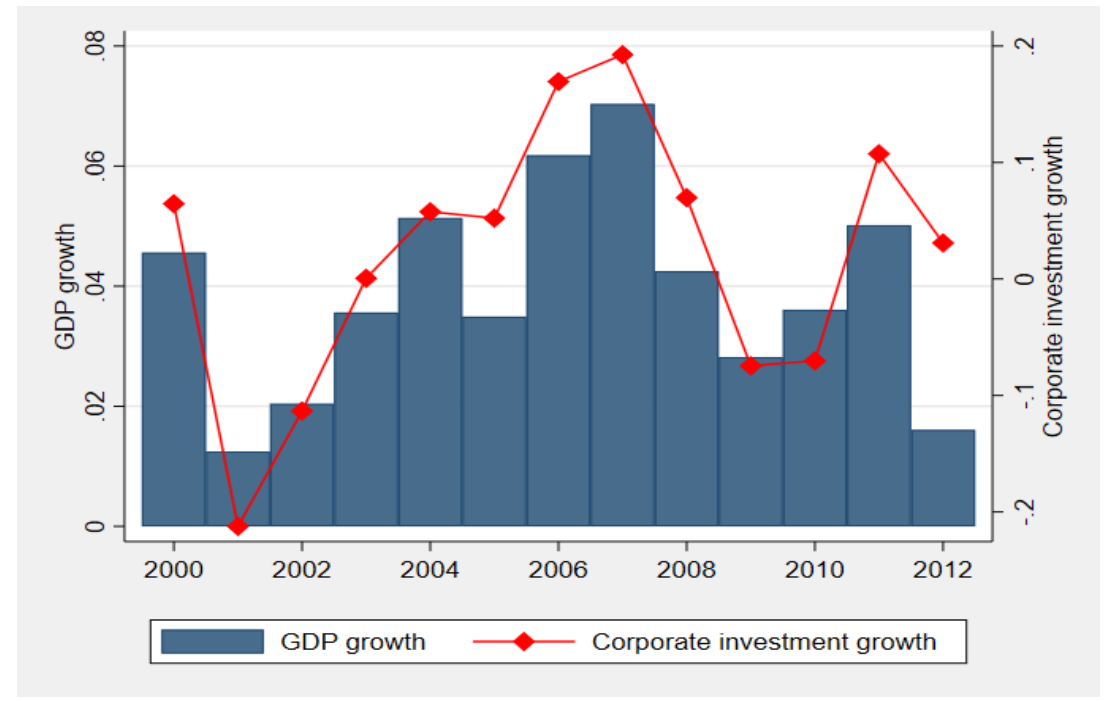

Note: Annual growth rate of gross fixed capital formation of non-financial corporations is plotted on the right axis. Annual GDP growth is plotted on the left axis. Source: Eurostat.

\section{FURTHER ROBUSTNESS}

\section{D.1 AVERAGE InVESTMENT PATTERNS}

Average investment patterns across years before and after the reform are useful for a variety of reasons. For the pre-reform period, estimated year-by-year coefficients allow us to examine common trends between treated and control groups. For the post-reform period, to the extent that investment responses demonstrate significant changes over the years, we may observe delayed responses due to learning about the policy or adjustment costs.

In Section 5.1, we show that average investment for treated and control groups follow common trends in the pre-reform period for both samples. In Figure 7, treated firms clearly increase their average investment after the reform, while Figure 8 shows that there is no clear differential increase in investment of treated firms after the reform in the high 
volatility period. In Figure A.2 and Figure A.3, we estimate year-by-year coefficients on Treatment $\times$ Post-reform for the first and the second reform period, respectively. The error bars represent 95 percent confidence intervals.

Figure A.2. Year-by-year investment patterns, low volatility period

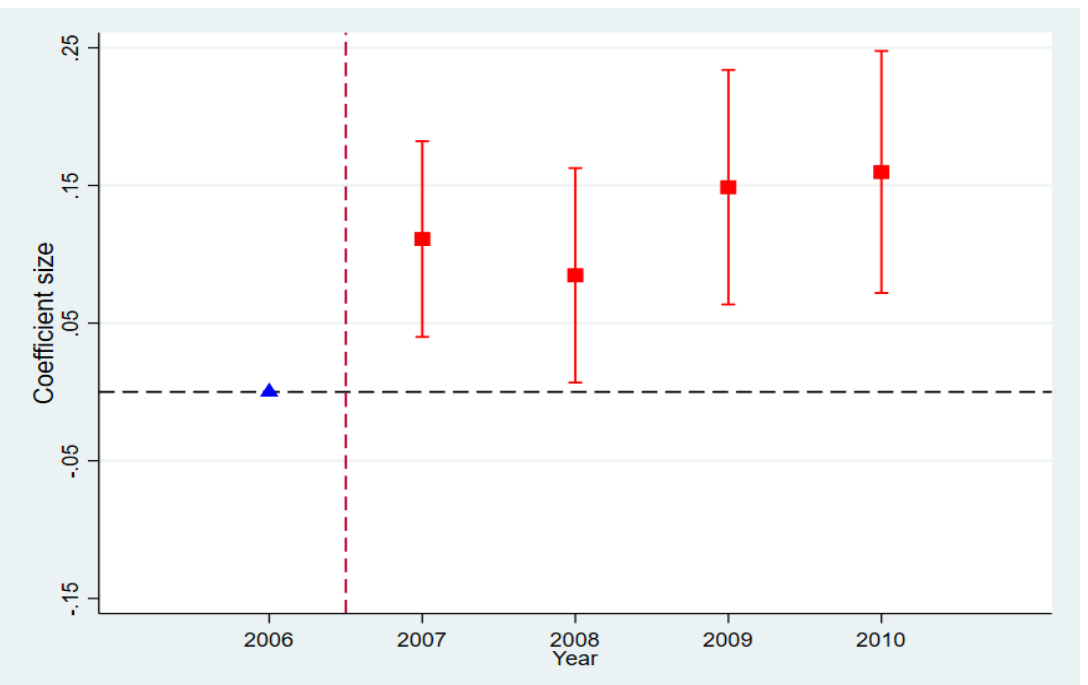

Note: This figure presents the point estimates with $95 \%$ confidence intervals for the $\gamma_{k}$ coefficients from the regression specification: $I_{i t}=\sum_{k=2006}^{2010} \gamma_{k} D_{i} T_{k}+\eta_{i}+\delta_{t}+\mathrm{X}_{i t}^{\prime} \beta+\psi_{s t}+\varepsilon_{i t}$, where $D_{i}$ is a dummy variable that takes the value unity for treated firms and zero otherwise, $T_{t}$ is a dummy variable that takes the value unity only for one period, that is, year $k$, and zero otherwise, $\eta_{i}$ represent firm fixed effects, $\delta_{t}$ represent year fixed effects. We normalise $\gamma_{2006}=0$. Blue dashed error bars and triangles represent the point estimate and confidence intervals for pre-reform years and the red solid error bars and squares represent the point estimate and confidence intervals for post-reform years.

In the low volatility period, adjustment to the new average investment level appears swift and stable. This pattern in the low volatility period indicates that issues related to low take-up to account for our results in the high volatility period are unlikely for incorporated businesses. This is in line with the evidence from the US that Kitchen and Knittel (2016) show in relation to special depreciation provisions.

Zooming in on the different size groups within each sample, in Figures A.4 and A.5, we plot average investment across 200,000 PLN (approximately 50,000-Euro) turnover bins for the pre-reform and the post-reform periods. In the low volatility period, treated firms (below the size threshold for eligibility) experience a hike in average investment between the pre-reform year of 2006 and the post-reform year of 2007 for virtually all treated size bins that we show in this graph. This jump is much smaller for average investment of firms in size bins that are larger than the threshold turnover size that applies in the first reform period.

In contrast to Figure A.4, we do not observe any increase in investment for treated firms in the second reform period (Figure A.5). If anything, we observe a drop in average investment from 2008 to 2010 for all size bins that we depict in the high volatility period. 
Figure A.3. Year-by-year investment patterns, high volatility period

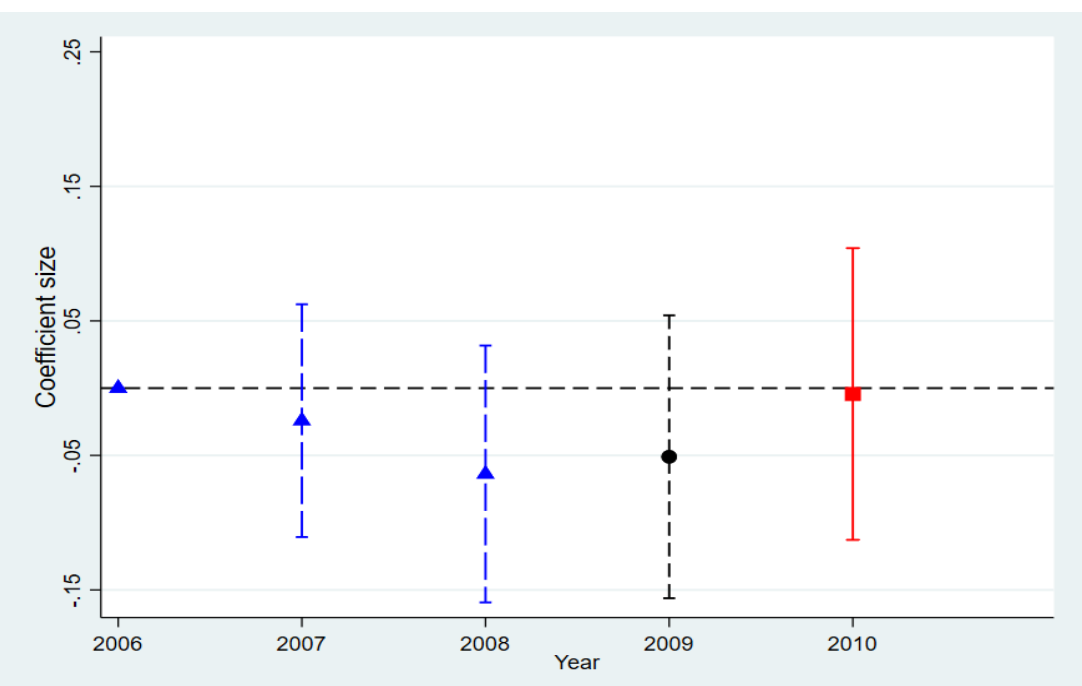

Note: This figure presents the point estimates with $95 \%$ confidence intervals for the $\gamma_{k}$ coefficients from the regression specification: $I_{i t}=\sum_{k=2006}^{2010} \gamma_{k} D_{i} T_{k}+\eta_{i}+\delta_{t}+\mathrm{X}_{i t}^{\prime} \beta+\psi_{s t}+\varepsilon_{i t}$, where $D_{i}$ is a dummy variable that takes the value unity for treated firms and zero otherwise, $T_{t}$ is a dummy variable that takes the value unity only for one period, that is, year $k$, and zero otherwise, $\eta_{i}$ represent firm fixed effects, $\delta_{t}$ represent year fixed effects. We normalise $\gamma_{2006}=0.2009$ is a partial treatment year and therefore marked with black dashed bars. Blue dashed error bars and triangles represent the point estimate and confidence intervals for pre-reform years and the red solid error bars and squares represent the point estimate and confidence intervals for post-reform years.

Figure A.4. Average investment by size groups, low volatility period

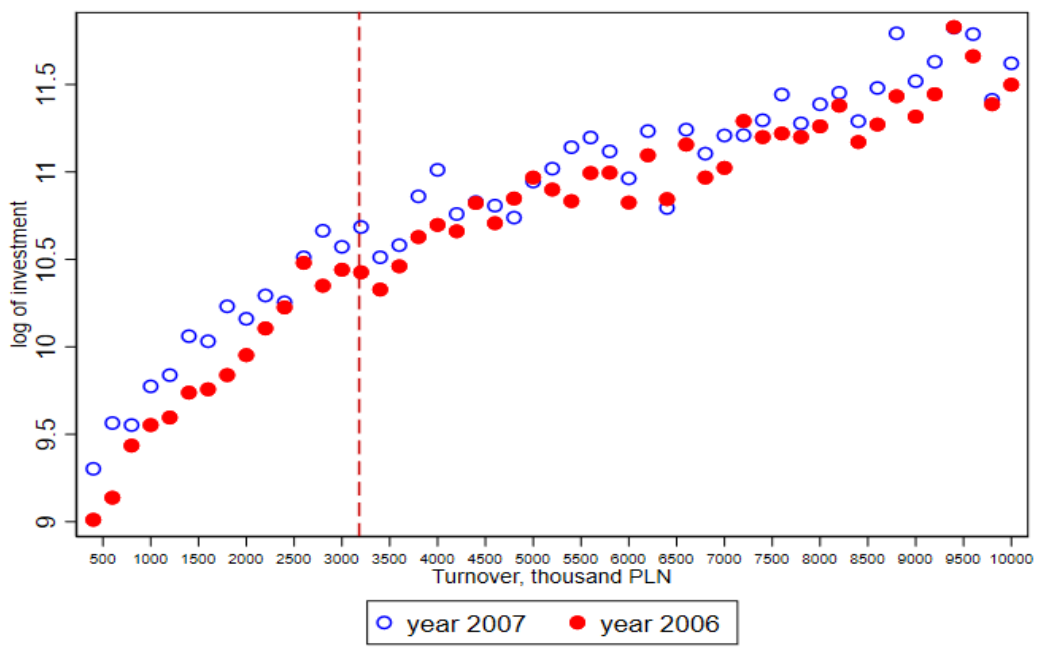

Note: This graph plots average investment for companies across 200 thousand PLN turnover bins in the last pre-reform period and the first post-reform period. The pre-treatment values are represented by red dots and the post-treatment values are represented by blue circles. The reference turnover ranges are based on 2006, which is the statutory reference year to determine eligibility to treatment. 
Figure A.5. Average investment by size groups, high volatility period

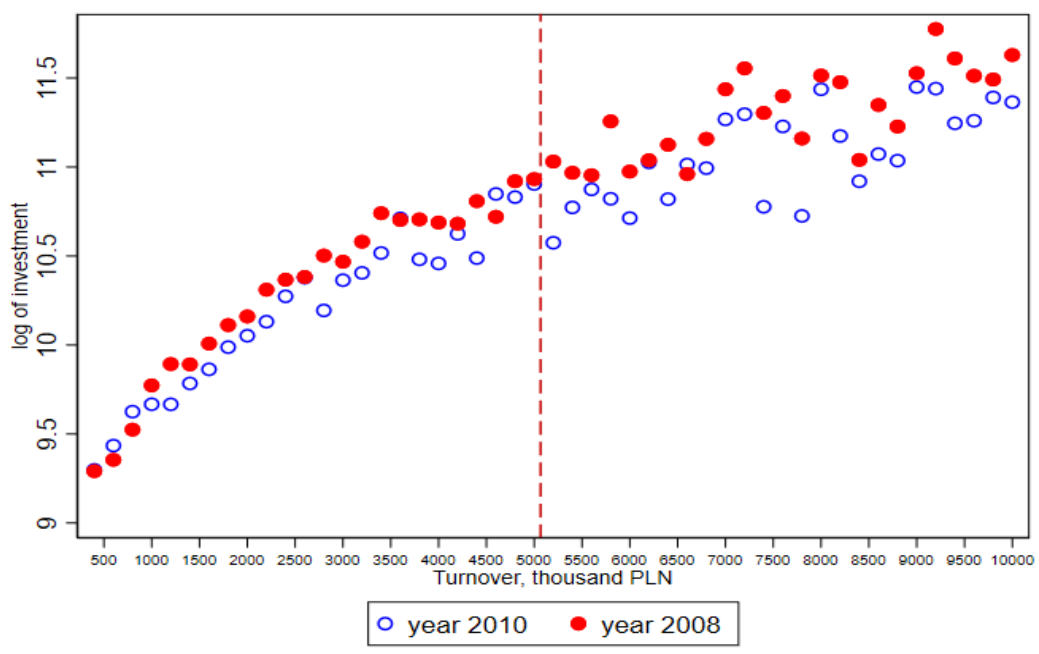

Note: This graph plots average investment for companies across 200 thousand PLN turnover bins in the last pre-reform period and the first post-reform period (excluding the partial treatment year 2009). The pre-treatment values are represented by red dots and the post-treatment values are represented by blue circles. The reference turnover ranges are based on 2009, which is the statutory reference year to determine eligibility to treatment.

We hypothesize that the weaker policy impact is due to increased uncertainty, and we show evidence that supports this hypothesis in Section 5. 


\section{D.2 Analysis using Quarterly Data}

As another robustness check, we use high frequency data to exploit the timing of changes in the treatment status within the second experiment. Recall that the eligibility turnover threshold was increased in two steps. First, the EUR denominated threshold was raised in May 2009. The PLN denominated threshold was further increased in January 2010 due to the currency depreciation that occurred after October 2008. In our baseline analysis, we drop year 2009 and analyse the investment response to treatment only in 2010.

In the analysis below, the post-reform period consists of the second half of 2009 and the entire 2010. The pre-reform period covers the 2008 and the first quarter of 2009 . The firm treatment status is consistent with the contemporary rules of the Lump Sum Depreciation scheme. We therefore allow the treatment status of a firm to vary between 2009 and 2010. We use the same sample of firms as in the baseline second experiment. Therefore, none of these firms was treated in 2008. If a firm is treated in the first quarter of 2009, we code this single quarterly observation as missing.

Quarterly analysis is not our preferred approach because of many observations in which investment equals zero. These observations would be dropped from the specification with log of investment as the dependent variable. In the period of the second experiment, non zero observations constitute only $38 \%$ of the treated sample and $55 \%$ of the control group sample. The zeros may distort interpretation of the intensive margin analysis. Consider an example, where a firm invest 25 dollars in each quarter in a pre-reform year and 50 dollars in only two quarters in a post-reform year. A logarithmic specification would drop zeros and show an increase on the intensive margin in a postreform year. That is why we focus on Poisson regressions that takes into account both intensive and extensive margin effects.

The results are consistent with the findings from the annual analysis. In the environment of high uncertainty, the investment response of more exposed firms is indistinguishably different from zero, while less exposed firms respond strongly to the policy. 
Table A.2. Quarterly analysis of investment responses

\begin{tabular}{|c|c|c|c|}
\hline $\begin{array}{l}\text { Sample } \\
\text { Dep.var: } I_{t}\end{array}$ & $\begin{array}{l}\text { Low vol. } \\
\text { (1) }\end{array}$ & $\begin{array}{l}\text { High vol. } \\
(2)\end{array}$ & $\begin{array}{l}\text { High vol. } \\
(3)\end{array}$ \\
\hline Treated $\times$ Post Reform & $\begin{array}{l}0.113^{* * *} \\
(0.037)\end{array}$ & $\begin{array}{l}0.089^{* *} \\
(0.039)\end{array}$ & $\begin{array}{l}0.128^{* * *} \\
(0.046)\end{array}$ \\
\hline Treated $\times$ Post Refom $\times$ High Exposure & & & $\begin{array}{l}-0.092 \\
(0.081)\end{array}$ \\
\hline Post Reform $\times$ High Exposure & & & $\begin{array}{l}-0.060^{*} \\
(0.036)\end{array}$ \\
\hline Turnover control (lagged, in log)? & Yes & Yes & Yes \\
\hline Turnover control (quart. dummies)? & Yes & Yes & Yes \\
\hline Firm fixed effects? & Yes & Yes & Yes \\
\hline Period effects? & Yes & Yes & Yes \\
\hline Exporter-/importer cont.? & Yes & Yes & Yes \\
\hline No of observations & 78551 & 71913 & 71913 \\
\hline $\begin{array}{l}\text { p-val. Coeff. on Treated } \times \text { Post Reform } \times \\
+ \text { Coeff. on Treated } \times \text { Post Reform }=0\end{array}$ & High E & sure & 0.598 \\
\hline
\end{tabular}

Note: In this table, we present the results of Poisson regressions on the quarterly samples. Extreme values of dependent variable $I_{t}$ in levels are winsorised above the 95-th percentile value. In Column (1), we report results for the first experiment sample. In Column (2), we use the second experiment sample, where pre-reform period consists of 5 quarters (up to the first quarter of 2009) and the post-reform period covers 6 quarters (starting in the third quarter of 2009). Column (3) adds interaction with the exposure to uncertainty, similarly as in the table (4). $p$-value in the bottom row of this table represents the result of a test of the hypothesis that the sum of the coefficients on (Treated $\times$ Post Reform $\times$ High Exposure) and (Treated $\times$ Post Reform) is equal to zero. 


\section{Oxford University Centre for Business Taxation Working Paper series recent papers}

WP 20/07 Irem Guceri and Maciej Albinowski, Investment Responses to Tax Policy Under Uncertainty

WP 20/06 Peter Morrow, Michael Smart and Artur Swistak VAT Compliance, Trade, and Institutions

WP 20/05 Daniel J.Hemel and David A.Weisbach The Behavioral Elasticity of Tax Revenue

WP 20/04 Daniel Shaviro What are Minimum Taxes and Why Might One Favor or Disfavor Them?

WP20/03 Aqib Aslam and Alpa Shah Tec(h)tonic Shifts: Taxing the "Digital Economy"

WP20/02 Ronald B. Davies, Dieter F. Kogler and Ryan Hynes Patent Boxes and the Success Rate of Applications

WP20/01 Richard Collier, Alice Pirlot and John Vella Tax policy and the COVID-19 crisis

WP19/16 Alice Pirlot Don't blame it on WTO law: An analysis of the alleged WTO law incompatibility of Destination-Based Taxes

WP19/15 Irem Güçeri and Maciej Albinowski Investment Responses to Tax Policy under Uncertainty

WP19/14 David R. Agrawal and David E. Wildasin Technology and Tax Systems

WP19/13 Alice Pirlot Exploring the Impact of European Union Law on Energy and Environmental Taxation

WP19/12 Michael Devereux How should business profit be taxed? Some thoughts on conceptual developments during the lifetime of the IFS

WP19/11 Sarah Clifford and Panos Mavrokonstantis Tax Enforcement using a Hybrid between Self- and Third-Party Reporting

WP19/10 Miguel Almunia, Irem Guceri, Ben Lockwood, Kimberley Scharf More giving or more givers? The effects of tax incentives on charitable donations in the UK

WP19/09 Itai Grinberg Stabilizing "pillar one" corporate profit reallocation in an uncertain environment

WP19/08 Joel Slemrod, Obeid Ur Rehman, Mazhar Waseem Pecuniary and non-pecuniary motivations for tax compliance: evidence from Pakistan 
WP19/07 Enda Hargaden, Barra Roantree Does statutory incidence matter? Earnings responses to social security contributions

WP19/06 Lucie Gadenne, Tushar K. Nandi, Roland Rathelot Taxation and supplier networks: evidence from India

WP19/05 Thiess Buettner, Boryana Madzharova Unit sales and price effects of preannounced consumption tax reforms: micro-level evidence from European VAT

WP19/04 Katarzyna Bilicka, Yaxuan Qi, Jing Xing Debt reallocation in multinational firms: evidence from the UK worldwide debt cap

WP19/03 Reuven Avi-Yonah, Orli Avi-Yonah, Nir Fishbien and Haiyan Xu Bridging the redblue divide: a proposal for US Regional Tax Relief

WP19/02 Elizabeth Gugl, George R. Zodrow Tax competition and the efficiency of "benefitrelated" business taxes

WP19/01 Michael P Devereux, Alan Auerbach, Michael Keen, Paul Oosterhuis, Wolfgang Schön and John Vella Residual profit allocation by income

WP18/22 Ronny Freier, Martin Simmler and Christian Wittrock Public good provision, commuting and local employment

WP18/21 Christian Wittrock Localization Economies and the Sensitivity of Firm Foundations to Changes in Taxation and Public Expenditures

WP18/20 Nadine Riedel, Martin Simmler and Christian Wittrock Local fiscal policies and their impact on the number and spatial distribution of new firms

WP18/19 Leonie Hug and Martin Simmler How cost-effective is public R\&D in stimulating firm innovation?

WP18/18 Wiji Arulampalam and Andrea Papini Tax Progressivity and Self-Employment Dynamics

WP18/17 Wiji Arulampalam, Michael P Devereux and Federica Liberini Taxes and the Location of Targets

WP18/16 Frank M Fossen, Ray Rees, Davud Rostam-Afschaf and Viktor Steiner How do Entrepreneurial Portfolios Respond to Income Taxation

WP18/15 Sebastian Beer, Ruud de Mooij and Li Liu International Corporate Tax Avoidance: A Review of the Channels, Magnitudes and Blind Spots 
WP18/14 Daisy Ogembo Are Presumptive Taxes a Good Option for Taxing Self-Employed Professionals in Developing Countries

WP18/13 Ilan Benshalom The Rise of Inequality and the fall of Tax Equity

WP18/12 Thomas Torslov, Ludwig Weir and Gabriel Zucman The Missing Profits of Nations

WP18/11 Andrea Lassman and Benedikt Zoller-Rydzek Decomposing the Margins of Transfer Pricing

WP18/10 Travis Chow, Jeffrey L Hoopes and Edward L Maydew US Firms on Foreign (tax) Holidays

WP18/09 Claudio Agostini, Juan Pablo Atal and Andrea Repetto Firms Response to Tax Enforcement through Audits

WP18/08 Mazhar Waseem Information, Asymmetric Incentives or Withholding? Understanding the Self-Enforcement of Value-Added-Tax

WP18/07 Matthew Smith, Danny Yagan, Owen Zidar and Eric Zwick Capitalists in the twenty-first century

WP18/06 Daniel Shaviro The new non-territorial U.S international tax system

WP18/05 Eric M Zolt Tax Treaties and Developing Countries

WP18/04 Anne Brockmeyer, Marco Hernandez, Stewart Kettle and Spencer Smith Casting a wider tax net: Experimental evidence from Costa Rica

WP18/03 Ruud de Mooij and Li Liu At a cost:the real effects of transfer pricing regulations

WP18/02 Rita de la Feria Tax fraud and the rule of law

WP18/01 Eddy Hiu Fung Tam Behavioural response to time notches in transaction tax: Evidence from stamp duty in Hong Kong and Singapore

WP17/19 Michael P. Devereux, Giorgia Maffini and Jing Xing Corporate tax incentives \& capital structure: New evidence from UK firm-level tax returns

WP17/18 Sarah Clifford Taxing Multinationals beyond borders: financial and locational responses to CFC rules

WP17/17 Dominik von Hagen and Axel Prettl Controlled foreign corporation rules and crossborder M\&A activity

WP17/16 Marie Lamensch Destination based taxation of corporate profits - preliminary findings regarding tax collection in cross-border situations 
WP17/15 Li Liu Tim Schmidt-Eisenlohr and Dongxian Guo International transfer pricing and tax avoidance: Evidence from linked trade-tax statistics in the UK.

WP17/14 Katarzyna Habu How much tax do companies pay in the UK?

WP17/13 Katarzyna Habu How aggressive are foreign multinational companies in reducing their corporation tax liability?

WP17/12 Edward D. Kleinbard The right tax at the right time

WP17/11 Aaron Flaaen The role of transfer prices in profit-shifting by U.S. multinational firms: Evidence from the 2004 Homeland Investment Act

WP17/10 Ruud de Mooij and Li Liu At a cost: The real effect of transfer pricing regulations on multinational investments

WP17/09 Wei Cui Taxation without information: The institutional foundations of modern tax collection

WP17/08 John Brooks The definitions of income

WP17/07 Michael P. Devereux and John Vella Implications of Digitalization for International Corporation Tax Reform

WP17/06 Richard Collier and Michael P. Devereux The Destination-Based Cash Flow Tax and the Double Tax Treaties

WP17/05 Li Liu Where does multinational investment go with Territorial Taxation

WP17/04 Wiji Arulampalam, Michael P Devereux and Federica Liberini Taxes and Location of Targets

WP17/03 Johannes Becker and Joachim Englisch A European Perspective on the US plans for a Destination based cash flow tax

WP17/02 Andreas Haufler, Mohammed Mardan and Dirk Schindler Double tax discrimination to attract FDI and fight profit shifting: The role of CFC rules

WP17/01 Alan Auerbach, Michael P. Devereux, Michael Keen and John Vella Destinationbased cash flow taxation

WP16/14 Anzhela Cédelle The EU Anti-Tax Avoidance Directive: A UK Perspective

WP16/13 Michael Devereux Measuring corporation tax uncertainty across countries:

Evidence from a cross-country survey 
WP16/12 Andreas Haufler and Ulf Maier Regulatory competition in capital standards with selection effects among banks

WP16/11 Katarzyna Habu Are financing constraints binding for investment? Evidence from natural experiment

WP 16/10 Li Liu and Ben Lockwood VAT notches, voluntary registration and bunching: Theory and UK evidence

WP 16/09 Harry Grubert and Roseanne Altshuler Shifting the burden of taxation from the corporate to the personal level and getting the corporate tax rate down to 15 percent

WP 16/08 Margaret K McKeehan and George R Zodrow Balancing act: weighing the factors affecting the taxation of capital income in a small open economy

WP 16/07 Michael P Devereux and Li Liu Stimulating investment through incorporation

WP 16/06 Stephen R Bond and Irem Guceri R\&D and productivity: Evidence from large UK establishments with substantial $R \& D$ activities

WP16/05 Tobias Böhm, Nadine Riedel and Martin Simmler Large and influential: firm size and governments' corporate tax rate choice?

WP16/04 Dhammika Dharmapala The economics of corporate and business tax reform

WP 16/03 Rita de la Feria EU VAT principles as interpretative aids to EU VAT rules: the inherent paradox

WP 16/02 Irem Guceri Will the real R\&D employees please stand up? Effects of tax breaks on firm level outcomes

WP 16/01 Giorgia Maffini, Jing Xing and Michael P Devereux The impact of investment incentives: evidence from UK corporation tax returns

WP 15/33 Anzhela Cédelle Enhanced co-operation: a way forward for tax harmonisation in the EU?

WP 15/32 James Mahon and Eric Zwick Do experts help firms optimise?

WP 15/31 Robin Boadway, Motohiro Sato and Jean-François Tremblay Cash-flow business taxation revisited: bankruptcy, risk aversion and asymmetric information

WP 15/30 Martin Simmler Do multinational firms invest more? On the impact of internal debt financing and transfer pricing on capital accumulation 
WP 15/29 Daniel Shaviro The crossroads versus the seesaw: getting a 'fix' on recent international tax policy developments

WP 15/28 Zhonglan Dai, Douglas A Shackelford, Yue (Layla) Ying and Harold H Zhang Do companies invest more after shareholder tax cuts?

WP 15/27 Martin Ruf and Julia Schmider Who bears the cost of taxing the rich? An empirical study on CEO pay

WP 15/26 Eric Orhn The corporate investment response to the domestic production activities deduction

WP 15/25 Li Liu International taxation and MNE investment: evidence from the UK change to territoriality

WP 15/24 Edward D Kleinbard Reimagining capital income taxation

WP 15/23 James R Hines Jr, Niklas Potrafke, Marina Riem and Christoph Schinke Inter vivos transfers of ownership in family firms

WP 15/22 Céline Azémar and Dhammika Dharmapala Tax sparing agreements, territorial tax reforms, and foreign direct investment

WP 15/21 Wei Cui A critical review of proposals for destination-based cash-flow corporate taxation as an international tax reform option

WP 15/20 Andrew Bird and Stephen A Karolyi Governance and taxes: evidence from regression discontinuity

WP 15/19 Reuven Avi-Yonah Reinventing the wheel: what we can learn from the Tax Reform Act of 1986

WP 15/18 Annette Alstadsæter, Salvador Barrios, Gaetan Nicodeme, Agnieszka Maria Skonieczna and Antonio Vezzani Patent boxes design, patents, location and local R\&D

WP 15/17 Laurent Bach Do better entrepreneurs avoid more taxes?

WP 15/16 Nadja Dwenger, Frank M Fossen and Martin Simmler From financial to real economic crisis: evidence from individual firm-bank relationships in Germany

WP 15/15 Giorgia Maffini and John Vella Evidence-based policy-making? The Commission's proposal for an FTT

WP 15/14 Clemens Fuest and Jing Xing How can a country 'graduate' from procyclical fiscal policy? Evidence from China? 
WP 15/13 Richard Collier and Giorgia Maffini The UK international tax agenda for business and the impact of the OECD BEPS project

WP 15/12 Irem Guceri and Li Liu Effectiveness of fiscal incentives for R\&D: quasiexperimental evidence

WP 15/11 Irem Guceri Tax incentives and R\&D: an evaluation of the 2002 UK reform using micro data

WP 15/10 Rita de la Feria and Parintira Tanawong Surcharges and penalties in UK tax law

WP 15/09 Ernesto Crivelli, Ruud de Mooij, Michael Keen Base erosion, profit-shifting and developing countries

WP 15/08 Judith Freedman Managing tax complexity: the institutional framework for tax policy-making and oversight

WP 15/07 Michael P Devereux, Giorgia Maffini and Jing Xing Corporate tax incentives and capital structure: empirical evidence from UK tax returns

WP 15/06 Li Liu and Ben Lockwood VAT notches

WP 15/05 Clemens Fuest and Li Liu Does ownership affect the impact of taxes on firm behaviour? Evidence from China.

WP 15/04 Michael P Devereux, Clemens Fuest and Ben Lockwood The taxation of foreign profits: a unified view

WP 15/03 Jitao Tang and Rosanne Altshuler The spillover effects of outward foreign direct investment on home countries: evidence from the United States

WP 15/02 Juan Carlos Suarez Serrato and Owen Zidar Who benefits from state corporate tax cuts? A local labour markets approach with heterogeneous firms

WP 15/01 Ronald B Davies, Julien Martin, Mathieu Parenti and Farid Toubal Knocking on Tax Haven's Door: multinational firms and transfer pricing 